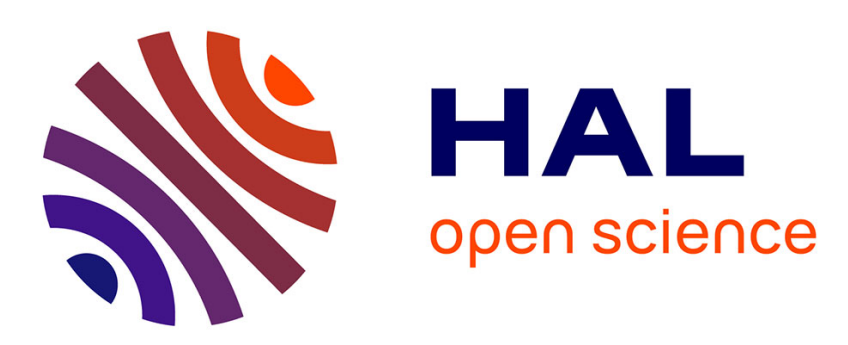

\title{
A simplified 2D model to study the contact-friction at the interfaces of steel-concrete composite beam-to-beam joint
}

Samy Guezouli, Sao Serey Kaing, Alain Lachal

\section{- To cite this version:}

Samy Guezouli, Sao Serey Kaing, Alain Lachal. A simplified 2D model to study the contact-friction at the interfaces of steel-concrete composite beam-to-beam joint. Engineering Structures, 2015, 84, pp.76-88. 10.1016/j.engstruct.2014.11.023 . hal-01121931

\section{HAL Id: hal-01121931 \\ https://hal.science/hal-01121931}

Submitted on 3 Mar 2015

HAL is a multi-disciplinary open access archive for the deposit and dissemination of scientific research documents, whether they are published or not. The documents may come from teaching and research institutions in France or abroad, or from public or private research centers.
L'archive ouverte pluridisciplinaire HAL, est destinée au dépôt et à la diffusion de documents scientifiques de niveau recherche, publiés ou non, émanant des établissements d'enseignement et de recherche français ou étrangers, des laboratoires publics ou privés. 


\title{
A simplified 2D model to study the contact-friction at the interfaces of steel-concrete composite beam-to-beam joint
}

\author{
Samy GUEZOULI*, Sao Serey KAING** and Alain LACHAL* \\ *National Institute of Applied Sciences (INSA) - Rennes - France \\ samy.guezouli@insa-rennes.fr \\ alain.lachal@gmail.com \\ ** Institute of Technology of Cambodia (ITC) - Phnom Penh - Cambodia \\ ksserey@yahoo.fr
}

\begin{abstract}
This paper deals with a numerical investigation of the behaviour of a new joint typology to connect continuously composite beams in bridges. This beam-to-beam joint consists of buttplates and headed stud anchors connected to a transverse concrete beam. It has been designed and tested under fatigue and monotonic loading. To describe the joint behaviour, a general 3D model is required. However, due to the nonlinearities involved (plasticity, cracking, contact, friction, etc.) the convergence of the iterative process is very difficult to reach with such a model. For an accurate interpretation of the test results and a better understanding of specific local behaviour, not accessible to measurement, an equivalent 2D finite element model has been proposed to approach the actual 3D problem. After calibration against experimental data, performances of this 2D model have been illustrated through two studies: the parametric influence of the butt-plate thickness and the internal force transfer mechanism in the joint.
\end{abstract}

\section{INTRODUCTION}

In order to promote new composite techniques for bridges, different solutions have been investigated for the design and the fabrication of beam-to-beam joints. In Europe, several projects have been carried out on this subject the past few years [1]. In France, taking benefit of a National Research Project, the Laboratory of Structural Mechanics at INSA in Rennes has undertaken research work to devise new types of beam-to-beam joint ensuring the continuity of composite beam in bridges. New joint typologies have been selected [2] with the aim to find economic solutions using, if possible, standardized or ordinary prefabricated elements easily mounted on site by the same builder with a minimum of construction operations and without any sophisticated technology (as outdoor welding for example). To point out that these joint solutions could be applied to buildings.

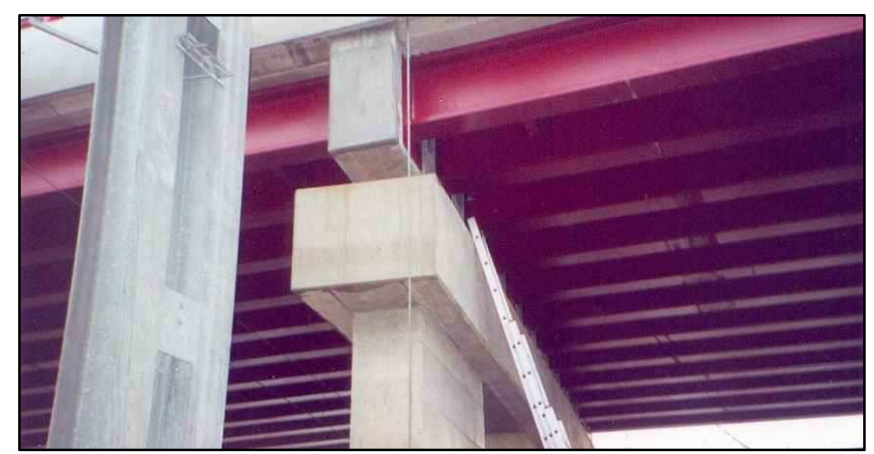

Figure 1 - Beam-to-beam joints with butt-plates connected to a transverse concrete beam in a multi-beam composite bridge. 
Approximately half-scale specimens of typical medium-span bridges as the one presented in Figure 1 (Wilson bridge, Villeneuve Saint-Georges, France) have been tested on the platform of the Laboratory under fatigue and monotonic increasing loading up to the specimen collapse. The analysis of the test results has provided a rich set of experimental data on the overall joint behaviour and also on internal force values in different parts of the studied specimens. Taking advantage of this set of data and in order to allow a thorough interpretation of test results, several numerical models were developed [3]. Finelg [4] and Cast3M [5] codes were firstly used for the development of these numerical models. Initially, preliminary numerical work has been rather aimed to develop a 3D F.E. model involving multi-plate and shell elements together with beam elements or 3D solid elements [3]. It is worth to mention that at the same period several authors have proposed similar 3D models ([6], [7], [8], [9], [10]) for the modeling of composite sub-structure for buildings or bridges. Based on a review of the literature dealing with advanced F.E. modeling as well as our own experience with such models; one can conclude that 3D F.E. models are usually able to predict reasonably accurate results in terms of global variables such as load-displacement or moment-rotation. On the other hand, when comparing the prediction of these models against local experimental data (as strain/stress results for example), the discrepancy was often quite significant, specifically around the contact zones between different materials. It is well known that frictional contact problems are very stiff and thereby generates convergence problems during the 3D F.E. calculation. For this reason, several authors have chosen not to represent frictional contact interactions in their 3D models ([11], [12], [13], [14]).

Taking benefit of the experience gained through these various attempts and keeping in mind the aim of developing a model able to give significant stress and strain local results, the authors have turned to the development of a 2D numerical model. Indeed, a 2D model where the number of DOF is reduced insures a better convergence of the iterative process and consequently facilitates the realization of parametric studies. The introduction of contact/friction elements between steel and concrete materials is simpler and safer in 2D than in 3D models because the contact is line-to-line in first case and face-to-face in second case.

To perform this modeling, the authors had first to show that the truly 3D problem could be properly reduced to a 2D model. This was done starting from a series of push-out tests carried out previously at the Laboratory and for which a $2 \mathrm{D}$ nonlinear finite element model was developed $[15,16]$. The push-out specimen was reduced to the reference plane of the steel beam web. Comparisons of the 2D numerical results against experimental data have shown that the third dimension (perpendicular to the plane stress model) had a limited influence on the results. Some calibrations (material and friction characteristics for example) performed during the modeling of push-out tests were retained for the study presented in this paper.

The paper is organized as follows: In Section 1, the geometrical and mechanical characteristics of the joint tested at the laboratory of INSA-Rennes are firstly presented. The test set-up and the type of loading applied to the specimen during the test are also indicated. The 2D equivalent model is introduced in Section 2. The methodology to derive the material properties is given in details. The "zone-equivalence" methodology used to reduce the truly 3D problem to a simplified 2D nonlinear model is presented. Constitutive models as well as frictional contact interactions are also provided. In Section 3 and Section 4, the proposed model is calibrated against several experimental data.

In order to show the performance of the 2D developed model, two studies have been undertaken: 
The first one, presented in Section 5, concerns the parametric influence of the butt-plate thickness on internal forces transmitted through the joint and more particularly by the stud anchors of the butt-plate.

The second one, undertaken in Section 6, is a general approach for the internal force-transfer mechanism through the joint.

To summarize, the main objectives of the paper are:

- To develop a 2D model able to give significant stress and strain results in a composite beam-to-beam joint as the one presented in this paper.

- To show that the developed 2D model is an efficient tool to perform parametric studies.

- To evaluate the part of the shear force transmitted by friction through the joint.

- In addition to the test results, to give a better understanding of the transfer-mechanism of internal forces through the joint.

\section{THE EXPERIMENTAL TEST}

The specimen tested at the Laboratory of Structural Mechanics (INSA- Rennes) is presented in Figures 2.a, 2.b and 2.c. It includes two composite beams connected to a massive reinforced concrete block which represents a part of the reinforced concrete transverse beam of a real bridge resting on the entire length of a pier head through neoprene supports (for the rest of the paper and in order to clarify the text, the "massive concrete block" will be called "concrete transverse beam"). The concrete transverse beam is simply supported at mid-length of the specimen on a neoprene plate resting on a support. Two vertical loads are exerted at the two ends of the specimen. Beam lengths were chosen in order to obtain a realistic ratio between the shear force and the hogging bending moment transmitted by the beams to the concrete transverse beam through the joints. Each composite beam is made of a HEA 500 steel section shear connected to a concrete (C40/50) slab. Transverse slab dimensions are $b=$ $1600 \mathrm{~mm}$ and $h_{c}=160 \mathrm{~mm}$. The slab width $b$ was defined as the effective width $b_{\text {eff }}^{-}$in hogging bending. According to [17], an effective width of $1600 \mathrm{~mm}$, equal to the width of the slab, was adopted for the concrete transverse beam. The composite beams are connected to the concrete transverse beam by means of butt-plates whose dimensions are $(600 \times 520 \times 45)$. The butt-plate thickness of $45 \mathrm{~mm}$ was chosen in order to ensure a sufficient diffusion of the compressive force transmitted by the bottom flange of the steel section. Effectively, as it will be seen later in Section 4.2 of this paper, the butt-plate thickness has a real influence on intensity of compressive stresses in the part of the concrete transverse beam located near the bottom flange of the steel section. Each butt-plate was equipped with 15 horizontal welded headed stud anchors (the same as those used to connect the slab; see Table 1) distributed on 5 rows and 3 lines ensuring the connection between steel sections of the composite beams and the concrete transverse beam. 

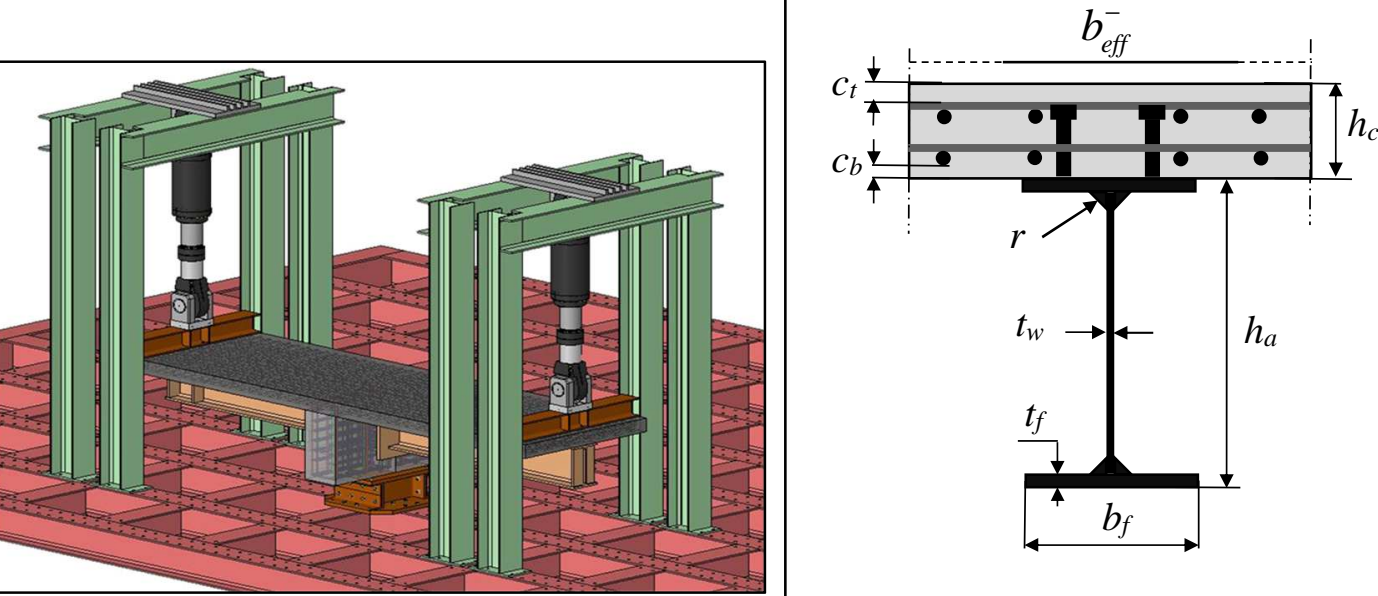

Figure 2.a - Experimental test: 3D view. Figure 2.b - Composite cross-section (Slab2).

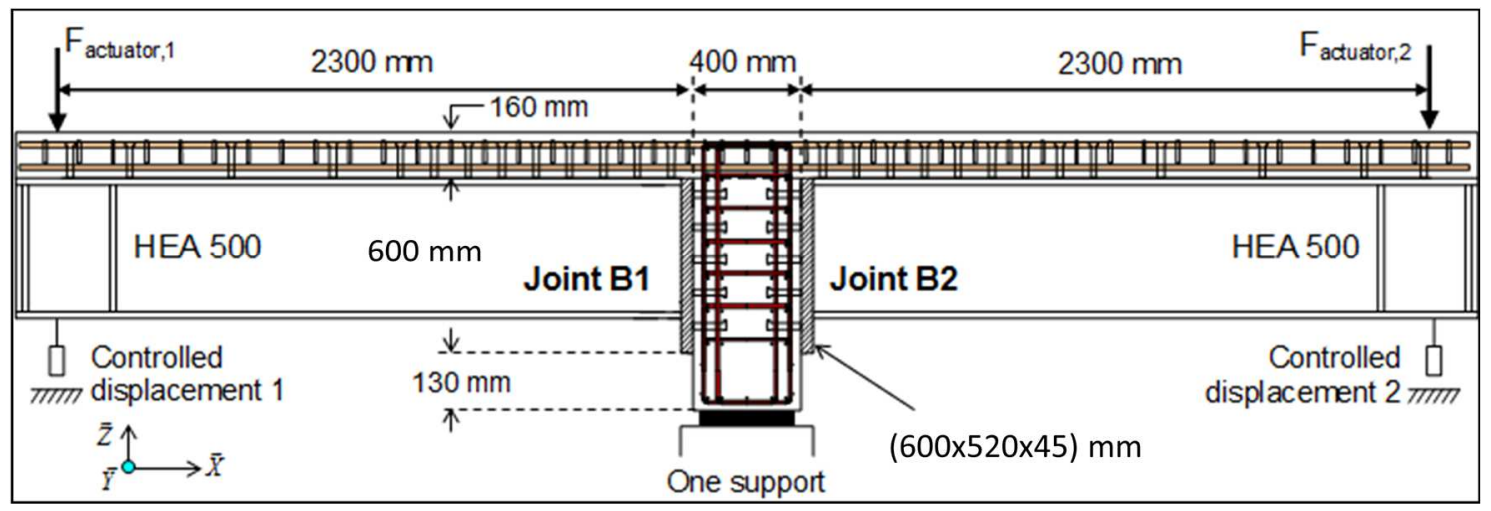

Figure 2.c - Experimental test: Dimensions.

Actually, two joints on each side of the concrete transverse beam have to be distinguished. A joint labeled B1 on the left-hand side and a joint labeled B2 on the right-hand side. For joint B1 the butt-plate is welded with the steel beam with a fillet weld whereas for joint B2 a full penetration butt weld is used. No difference was observed during the test between these two welded solutions and so, this difference of welding was not taken into account in the numerical modeling and the assumption of a perfect vertical symmetry (Z-axis in Figure 4) has been kept.

Geometrical characteristics of the composite cross-section are reminded in Table 1.

Table 1 - Geometrical characteristics of the composite cross-section (mm).

\begin{tabular}{|c|c|c|c||c|c|c|c|c||c|c|c|c|}
\hline Material & \multicolumn{3}{|c||}{ Slab } & \multicolumn{4}{c||}{ HEA500 } & \multicolumn{4}{c|}{ Stud } \\
\hline Characteristics & $h_{c}$ & $c_{b}$ & $c_{t}$ & $t_{w}$ & $b_{f}$ & $t_{f}$ & $h_{a}$ & $r$ & $d_{2}$ & $h_{s c}$ & $d_{l}$ & $k$ \\
\hline Value $(\mathrm{mm})$ & 160 & 21 & 32 & 12 & 300 & 23 & 490 & 27 & 22 & 125 & 35 & 10 \\
\hline
\end{tabular}

Regarding the percentage of reinforcement and connection, we will distinguish two zones per span (Figures 2.c and 4). A zone called Slab2 where the percentage of reinforcement (and connection) would be the percentage of a continuous beam without joint. A zone called Slab1 near the joint where the slab has to ensure the transfer of internal tensile forces that would be transmitted by the steel girder flanges if the beam was continuous. Considering a halfspecimen, the lengths of the two zones are $1400 \mathrm{~mm}$ for Slab1 and $1150 \mathrm{~mm}$ for Slab2 (Figure 4). In Slab2 zone, the percentage of longitudinal reinforcement is $1.26 \%$. The reinforcement is 
composed of 2 layers of 8 ribbed bars - S500 of $16 \mathrm{~mm}$ diameter. This part of the slab is shear connected to the steel flange girders with 10 welded headed studs (Table 1): 2 lines of 5 welded headed studs. In Slab1 zone, the percentage of longitudinal reinforcement is increased to $2.67 \%$ (9 additional rebars of $16 \mathrm{~mm}$ diameter - S500 are added to the 2 layers of ribbed bars of Slab2 zone) and the number of headed studs is increased to 16 welded headed studs: 2 lines of 8 welded headed studs having the same mechanical characteristics as studs of Slab2 zone. The concrete transverse beam and the slab are concreted in same time and so with the same concrete material. The percentage of longitudinal reinforcement of the concrete transverse beam is equal to $1.26 \%$.

The experimental setup includes two hydraulic servo-controlled actuators. Each actuator applies a vertical load $\mathrm{F}$ at each beam end cross-sections of the specimen. Two types of servocontrolled loading displacement procedure were exerted (Figure 3): firstly, a fatigue loading of 110000 equivalent cycles under a $170 \mathrm{kN}$ range of the force $\mathrm{F}$ applied by each actuator with a frequency of $1 / 2$ Hertz and secondly, a monotonically increasing of actuator displacements towards the specimen collapse.

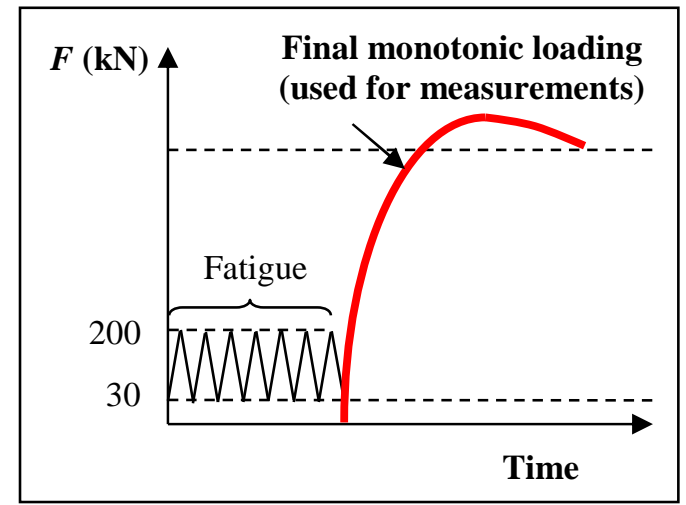

Figure 3 - Loading history.

Main measurement devices during the tests were: inclinometers, linear potentiometric transducers and strain gauges used to measure the joint rotation, deflections, relative displacements (slips) and strains at several parts of the specimen. Crack widths were measured on the top surface of the concrete slab.

Mechanical characteristics of each component of the joint are summarized in Table 2.

Table 2 - Mechanical characteristics.

\begin{tabular}{|c|c|}
\hline Component & Characteristics $(M P a)$ \\
\hline HEA 500 & $E_{a}=210000, f_{y, a}($ web $)=450, f_{y, a}($ flanges $)=520$ \\
\hline Butt-Plate & $E_{b p}=210000, f_{y, b p}=385$ \\
\hline Concrete slab & $E_{c m}=35200, f_{c k}=40 \rightarrow f_{c m}=48, f_{c t m}=3.5$ \\
\hline Rebars & $E_{s}=200000, f_{y, s}=585$ \\
\hline Studs & $E_{c}=200000$ and $f_{y, c}=529$ \\
\hline
\end{tabular}

\section{THE 2D F.E. MODEL}

The aim of this Section is to propose a representative 2D simplified model that insures a fast convergence of the iterative process, particularly when contact finite elements (line-contact) are used at the interface between materials. 3D F.E. model for joint with different materials are relatively complex with large number of DOF and often interpretation in terms of local 
stresses and strain may prove to be difficult. As a consequence, the load transfer mechanisms are difficult to identify and therefore hamper the development of mechanically-sound design models. In contrast, the output coming from 2D models is less important and one can take advantage of the 2D nature of the models to better interpret the results. Nevertheless, before reducing the actual $3 \mathrm{D}$ problem into a simplified but accurate $2 \mathrm{D}$, it appears important to proof that third dimensions of the specimen perpendicular to the $2 \mathrm{D}$ plane model (called hereinafter: "out-of-plane" dimensions) does not affect significantly the results. In previous companion papers $[15,16]$ different configurations of push-out tests have been modeled using the 2D proposed model. For each test, comparisons between obtained numerical results and corresponding experimental results have showed a quite negligible contribution of the out-ofplane effects (along the axis perpendicular to the web surface of the steel section of the pushout specimen) showing the ability of the 2D proposed model to simulate correctly the behaviour of composite sub-structure. Results of these first studies have been encouraging in pursuing the 2D F.E.M. modeling to simulate the composite beam-to-beam joint under investigation in this paper. In addition, these first studies allowed adjusting some internal parameters of the numerical modeling as it will be seen hereafter.

\section{1 "Zone-equivalence" method}

The proposed F.E. model takes benefit of the vertical symmetry of the specimen. The principle of the "zone-equivalence" method is to reduce the out-of-plane dimensions of the specimen to unity width in $Y$-axis direction. The method involves 2 stages:

\section{First stage - Homogenization principle:}

Original depths for each material encountered along $Y$-axis have been previously defined. They will be recalculated in accordance with the different zones identified from $\mathrm{A}$ to $\mathrm{K}$ in Figure 4.

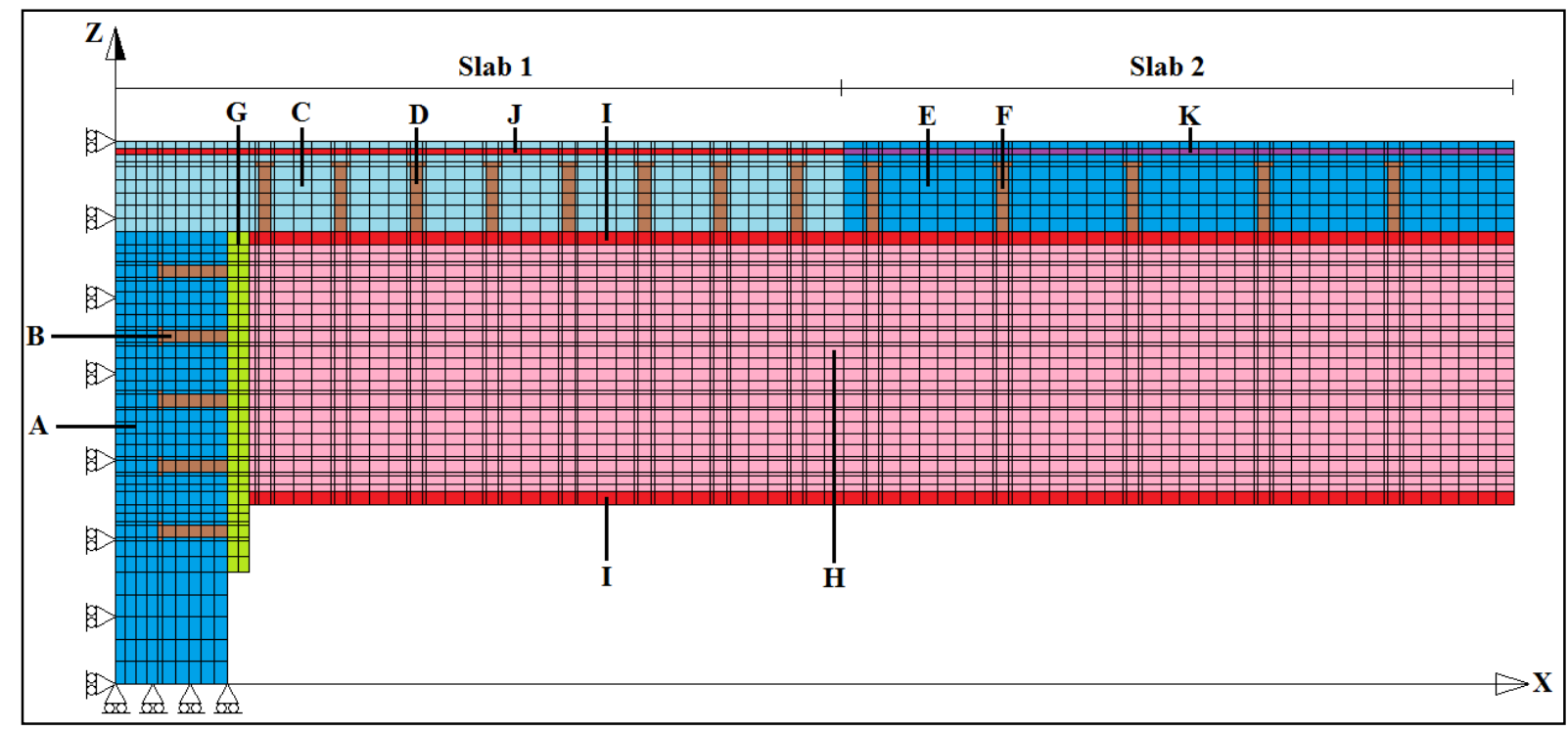

Figure $4-2 D$ F.E. mesh and boundary conditions.

Table 3 - First stage: Homogenization principle.

\begin{tabular}{|c|c|c|c|c|}
\hline Zone & Materials encountered & $\begin{array}{c}\text { Original } \\
\text { characteristics }\end{array}$ & $\begin{array}{c}\text { Equivalent } \\
\text { homogenized } \\
\text { material }\end{array}$ & $\begin{array}{c}\text { Equivalent } \\
\text { homogenized } \\
\text { material } \\
\text { depths } Y_{h}(\mathrm{~mm})\end{array}$ \\
\hline
\end{tabular}




\begin{tabular}{|c|c|c|c|c|}
\hline A & $\left\{\begin{array}{l}\text { Transverse beam concrete } \\
\text { Rebars }(1.26 \%)\end{array}\right.$ & $\left\{\begin{array}{l}l_{t b, e f f}=650 \mathrm{~mm} \\
p_{s}=1.26 \%\end{array}\right.$ & $\begin{array}{c}\text { Transverse beam } \\
\text { concrete }\end{array}$ & $688 \mathrm{~mm}$ \\
\hline B & $\left\{\begin{array}{l}\text { Transverse beam concrete } \\
\text { Rebars }(1.26 \%) \\
\text { Horizontal studs }\end{array}\right.$ & $\left\{\begin{array}{l}l_{t b, e f f}=650 \mathrm{~mm} \\
p_{s}=1.26 \% \\
3 \text { lines of } \Phi 22\end{array}\right.$ & Horizontal studs & $176 \mathrm{~mm}$ \\
\hline $\mathrm{C}$ & Slab concrete (Slab1) & $b_{c}=1600 \mathrm{~mm}$ & $\begin{array}{c}\text { Slab concrete } \\
(\text { Slab1) }\end{array}$ & $1600 \mathrm{~mm}$ \\
\hline $\mathrm{D}$ & $\left\{\begin{array}{l}\text { Slab concrete (Slab1) } \\
\text { Vertical studs }\end{array}\right.$ & $\left\{\begin{array}{l}b_{c}=1600 \mathrm{~mm} \\
2 \text { lines of } \Phi 22\end{array}\right.$ & Vertical studs & $318 \mathrm{~mm}$ \\
\hline $\mathrm{E}$ & Slab concrete (Slab2) & $b_{c}=1600 \mathrm{~mm}$ & $\begin{array}{l}\text { Slab concrete } \\
\text { (Slab2) }\end{array}$ & $1600 \mathrm{~mm}$ \\
\hline $\mathrm{F}$ & $\left\{\begin{array}{l}\text { Slab concrete (Slab2) } \\
\text { Vertical studs }\end{array}\right.$ & $\left\{\begin{array}{l}b_{c}=1600 \mathrm{~mm} \\
2 \text { lines of } \Phi 22\end{array}\right.$ & Vertical studs & $318 \mathrm{~mm}$ \\
\hline $\mathrm{G}$ & Butt-plate & $b_{b p}=520 \mathrm{~mm}$ & Butt-plate & $520 \mathrm{~mm}$ \\
\hline $\mathrm{H}$ & Steel beam web & $t_{w}=12 \mathrm{~mm}$ & Steel beam web & $12 \mathrm{~mm}$ \\
\hline $\mathrm{I}$ & Steel beam flanges & $b_{f}=300 \mathrm{~mm}$ & Steel beam flanges & $300 \mathrm{~mm}$ \\
\hline $\mathrm{J}$ & $\left\{\begin{array}{l}\text { Slab concrete }(\text { Slab1) } \\
\text { Rebars }(2.67 \%)\end{array}\right.$ & $\left\{\begin{array}{l}b_{c}=1600 \mathrm{~mm} \\
p_{s, 1}=2.67 \%\end{array}\right.$ & Rebars (Slab1) & $764 \mathrm{~mm}$ \\
\hline $\mathrm{K}$ & $\left\{\begin{array}{l}\text { Slab concrete (Slab2) } \\
\text { Rebars }(1.26 \%)\end{array}\right.$ & $\left\{\begin{array}{l}b_{c}=1600 \mathrm{~mm} \\
p_{s, 2}=1.26 \%\end{array}\right.$ & Rebars (Slab2) & $510 \mathrm{~mm}$ \\
\hline
\end{tabular}

\section{Remark about Zones A and B (Table 3):}

The compression force transmitted by the bottom steel flange is assumed to spread uniformly through the butt-plate thickness in bending under the bearing pressure and the width of the concrete of the transverse beam as shown in Figure 5. So, in order to model suitably the force-transfer mechanism towards the concrete transverse beam an effective length $l_{t b, e f f}$ has been defined as follows:

$$
l_{t b, e f f}=b_{f}+2 c+b_{t b} \tan \theta
$$

Where: $b_{f}$ is the width of the bottom flange of the steel section $\left(b_{f}=300 \mathrm{~mm}\right.$; see Table 1); the additional bearing width $(c=76 \mathrm{~mm})$ is calculated according to Section 6.2.5 of EN1993-1-8 [18]; $b_{t b}=400 \mathrm{~mm}$ is the (width of the transverse beam (Figure 2.c); and $\theta$ is the maximum angle of distribution of the compression force through the mid-width of the transverse beam $\left(\theta=26.5^{\circ}\right.$, see Section 6.7 of EN 1992-1-1 [19]). These values lead to $l_{t b, e f f}=650 \mathrm{~mm}$. 


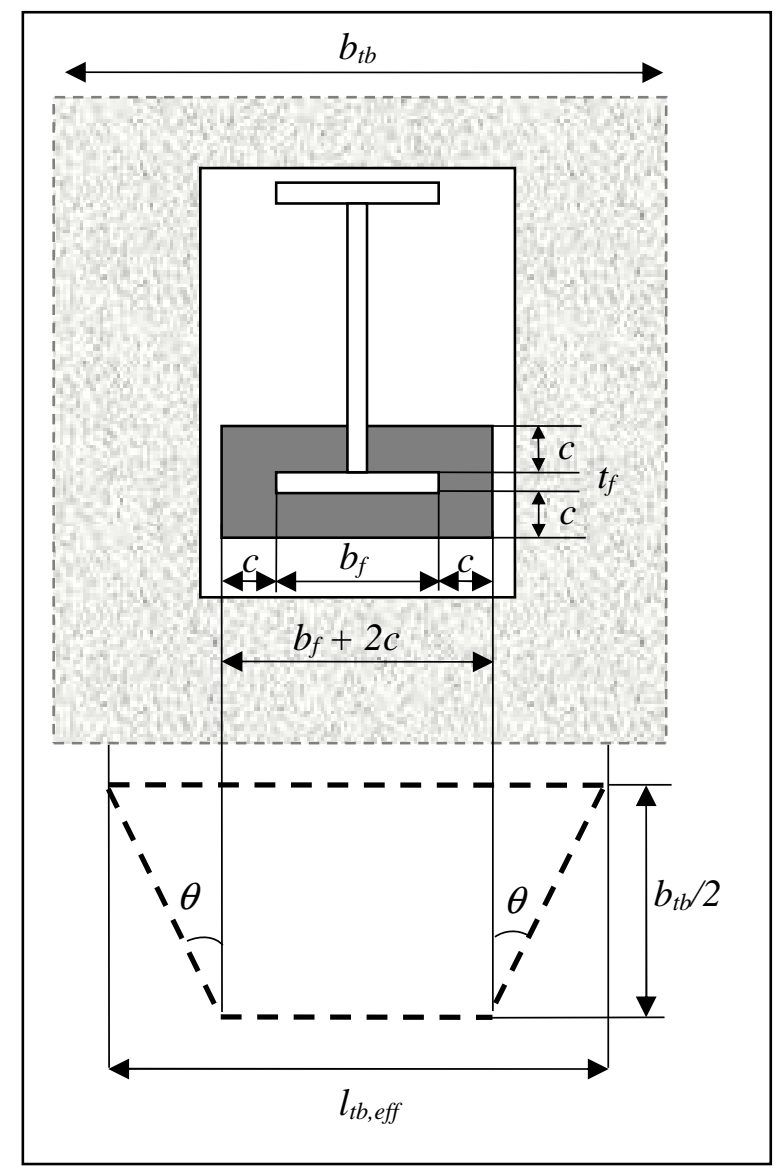

Figure 5 - Effective width of the contact (butt-plate - transverse beam).

The homogenization principle is used to get equivalent material for each zone. Table 3 gives also original materials encountered in $\mathrm{Y}$-axis direction and corresponding homogenized material. In this table, $p_{s}$ is the percentage of reinforcing bars in each concrete parts of the specimen. Only the zones: A, B, D, F, J and K (including steel and concrete materials) are concerned by homogenization principle. The equivalent homogenized material depths $Y_{h}$ are calculated as follows:

\section{Zone A:}

$$
Y_{h}=y_{t b}\left[1-\frac{p_{s}}{100}\left(1-n_{e q}^{\text {bars } \rightarrow \text { concrete }}\right)\right]
$$

$n_{e q}^{\text {bars } \rightarrow \text { concrete }}=\frac{E_{s}}{E_{c m}}$ is the equivalence coefficient used to replace reinforcing bars by equivalent concrete.

Zone B:

$$
Y_{h}=y_{t b} n_{e q}^{\text {concrete } \rightarrow \text { stud }}\left[1-\frac{p_{s}}{100}\left(1-\frac{n_{e q}^{\text {bars } \rightarrow \text { stud }}}{n_{e q}^{\text {concrete } \rightarrow \text { stud }}}\right)\right]+n d_{2}\left(1-n_{e q}^{\text {concrete } \rightarrow \text { stud }}\right)
$$


$n_{e q}^{\text {bars } \rightarrow \text { stud }}=\frac{E_{s}}{E_{c}}$ is the equivalence coefficient used to replace reinforcing bars by equivalent stud material.

$n_{e q}^{\text {concrete } \rightarrow \text { stud }}=\frac{E_{c m}}{E_{c}}$ is the equivalence coefficient used to replace transverse concrete beam by equivalent stud material.

$n$ is the number of stud anchors encountered in Y direction in the transverse concrete beam ( $n$ $=3$ lines) and $d_{2}=22 \mathrm{~mm}$ is the stud anchor diameter.

Zones D and F:

$$
Y_{h}=b_{c} n_{e q}^{\text {concrete } \rightarrow \text { stud }}+n d_{2}\left(1-n_{e q}^{\text {concrete } \rightarrow \text { stud }}\right)
$$

\section{Zones $\mathrm{J}$ and $\mathrm{K}$ :}

For the slab, it is suitable that the concrete and the rebars appear separately in order to be able to evaluate the tension magnitude in the rebars. In this case, no homogenization was carried out for the slab (Zones $\mathrm{C}$ and $\mathrm{E}$ - Table 3) except for the longitudinal fibre that represents the rebars. With the aim to simplified the mesh, this longitudinal fibre will have same height all along the specimen $\left(h_{0}\right)$. Nevertheless, the percentage of rebars in Slab1 $\left(p_{s, 1}=2.67 \%\right)$ is different than the one in Slab2 $\left(p_{s, 2}=1.26 \%\right)$, this difference will be included in the calculation of the homogenized rebar material depth of the corresponding fibre as follows:

$$
Y_{h}=b_{c} n_{e q}^{\text {concrete } \rightarrow \text { bars }}\left[1-\frac{p_{s, i} H}{100 h_{0}}\left(1-\frac{1}{n_{e q}^{\text {concrete } \rightarrow \text { bars }}}\right)\right]
$$

$P_{s, i}(i=1,2)$ is the percentage of reinforcing bars for each part of the slab (Slab1 and Slab2) and $n_{e q}^{\text {concrete } \rightarrow \text { bars }}=\frac{E_{c m}}{E_{s}}$ is the equivalence coefficient replacing slab concrete by equivalent reinforcing bars. Recall that $h_{c}$ is the slab height $(160 \mathrm{~mm})$. In this model, the height $h_{0}$ of equivalent rebar has been taken equal to $d_{s} / 3$; with $d_{s}$ the distance between the top of the vertical stud and the top of the slab.

\section{$\underline{\text { Second stage }-2 D \text { equivalence: }}$}

In second stage, original Young's moduli and yield stresses (Table 2) are respectively multiplied by the corresponding widths $Y_{h}$. Table 4 summarizes the mechanical characteristics for each equivalent material of the proposed $2 \mathrm{D}$ model.

Table 4. Mechanical characteristic adjustments for the simplified 2D model.

\begin{tabular}{|c|c|c|c|c|}
\hline \multirow{2}{*}{ Zone } & \multicolumn{2}{|c|}{ Young's moduli $(\mathrm{MPa})$} & \multicolumn{2}{c|}{$\begin{array}{c}\text { Yield stresses }(\mathrm{MPa}) \\
\text { Concrete }:\left(f_{\text {cm }}, f_{\text {ctm }}\right)\end{array}$} \\
\cline { 2 - 5 } & Actual 3D problem & Simplified 2D model & Actual 3D problem & Simplified 2D model \\
\hline A & 35200 & 24217600 & $(48,3.5)$ & $(33024,2408)$ \\
\hline B & 200000 & 35200000 & 529 & 93104 \\
\hline C & 35200 & 56320000 & $(48,3.5)$ & $(76800,5600)$ \\
\hline D & 200000 & 63600000 & 529 & 168222 \\
\hline E & 35200 & 56320000 & $(48,3.5)$ & $(76800,5600)$ \\
\hline
\end{tabular}




\begin{tabular}{|c|c|c|c|c|}
\hline $\mathrm{F}$ & 200000 & 63600000 & 529 & 168222 \\
\hline $\mathrm{G}$ & 210000 & 109200000 & 385 & 275080 \\
\hline $\mathrm{H}$ & 210000 & 2520000 & 450 & 6348 \\
\hline $\mathrm{I}$ & 210000 & 63000000 & 520 & 158700 \\
\hline $\mathrm{J}$ & 200000 & 152800000 & 585 & 446940 \\
\hline $\mathrm{K}$ & 200000 & 102000000 & 585 & 298350 \\
\hline
\end{tabular}

It worth to mention out that the mechanical characteristics, obtained for the simplified 2D model (Table 3), appear unrealistic because the width of the whole specimen is reduced to unity. Nevertheless, it could be possible to reduce this width to $1000 \mathrm{~mm}$ (for example) in order to obtain values comparable to the actual 3D problem ones. This will not change the results if one takes it into account during the post-processing stage. In this work the values are kept as they are given in Table 3.

\subsection{Equivalent 2D mechanical behaviours}

The equivalent 2D model and the actual 3D specimen should have same average deformation. This means that the mechanical behaviours should be adapted in accordance with mechanical characteristics of Table 4.

- For steel materials (web, flanges, studs, butt-plate and rebars), an elastic-plastic behaviour is used in tension as-well-as in compression with 5\% slope for hardening (Figure 6.a).

- For the concrete slab (Figure 6.b), a non-linear behaviour combines Rankine cracking model in tension with Drücker-Prager plastic model in compression. The tensile strengths $\left(\bar{f}_{c t m}\right.$ and $\bar{f}_{c m}$ ) and the ultimate strains ( $\varepsilon_{c t u}$ and $\varepsilon_{c u}$ ), in tension and in compression for both principal stress directions must be introduced in the model.

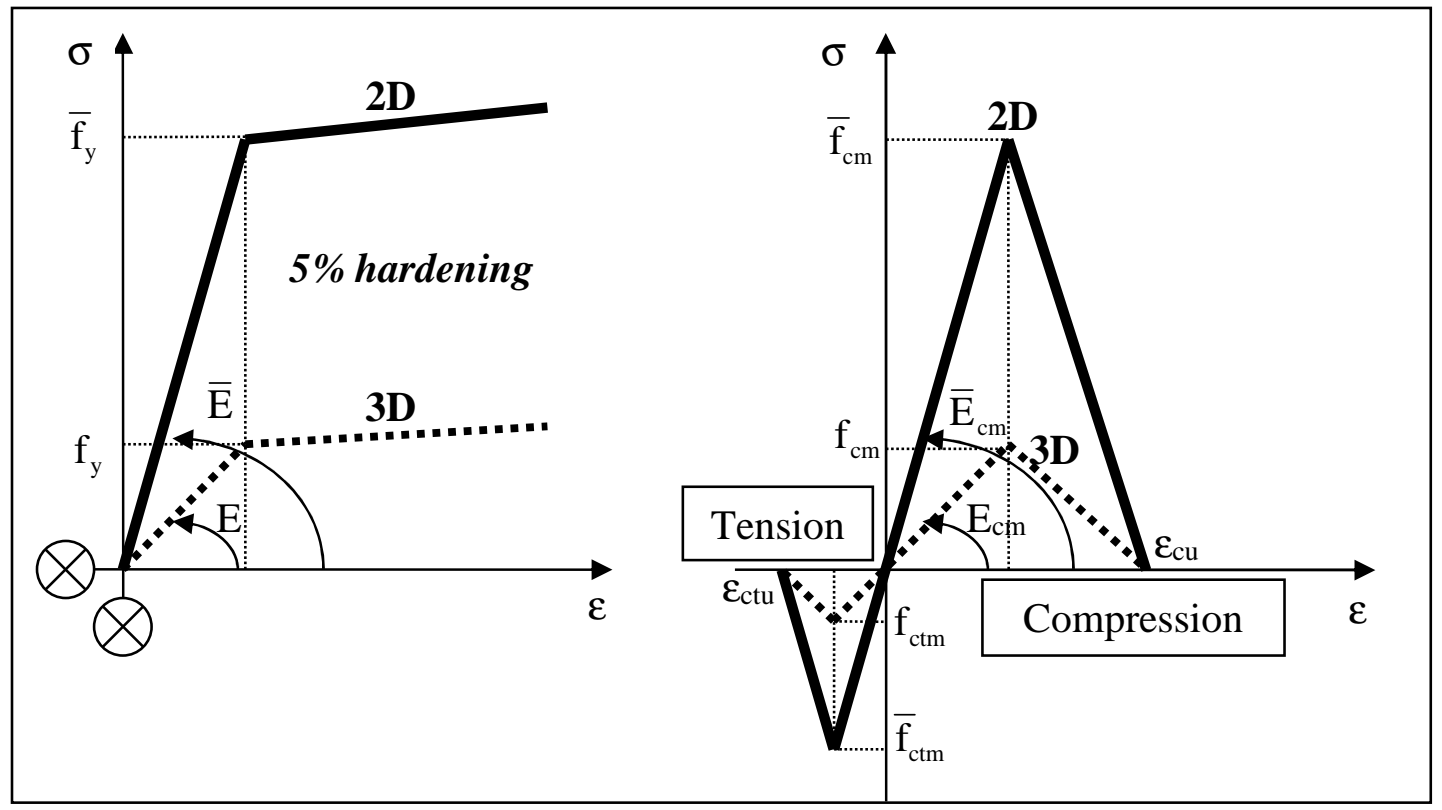

(a) - Steel.

(b) - Concrete.

Figure $6-2 \mathrm{D}-3 \mathrm{D}$ equivalent material behaviours.

\subsection{Contact-friction interfaces and loading conditions}


Contact finite element formulation used in the model is based on the kinematic method: contact without penetration and friction conditions are described kinematically at the nodes. They are expressed in terms of displacements and forces. In accordance with Figure 7, the normal relative displacement and corresponding normal force are $\left(U_{\mathrm{n}}, N\right)$ and tangent relative displacement with corresponding force are $\left(U_{\mathrm{t}}, T\right)$, both conditions can be written as follows:

- Contact without penetration condition:

$$
U_{n} \geq 0, \quad N \geq 0, \quad U_{n} N=0
$$

- Friction condition:

$$
\left(U_{t}>0 \Rightarrow-\vec{T}=\mu \vec{D}\right) \text { or }\left(U_{t}=0 \Rightarrow-\vec{T}<\mu \vec{D}\right)
$$

where: $\mu=\frac{T}{N}$ is the friction coefficient and $\vec{D}=\frac{\vec{U}_{t}}{\left|\vec{U}_{t}\right|}$.

Practically, two lines of nodes must be created, one for each material (Figure 7). These lines must be as close as possible (practically a gap of $1 / 10$ of the distance between two nodes of a same line) that makes the contact between the closer front-nodes. This precaution ensures good convergence of the iterative process. Figure 8 shows different contact-friction interfaces. According to the results of the numerical calibration undertaken in [15] and [16] against experimental results of 20 push-out tests, the following values of friction coefficient have been selected; a value of $\mu_{1}=0.3$ between the top flanges of the girders and the slab and at the butt-plates / transverse concrete beam interfaces; a value of $\mu_{2}=0.2$ between the headed studs and the concrete. A perfect adherence between the rebars and the concrete of the slab has been considered.

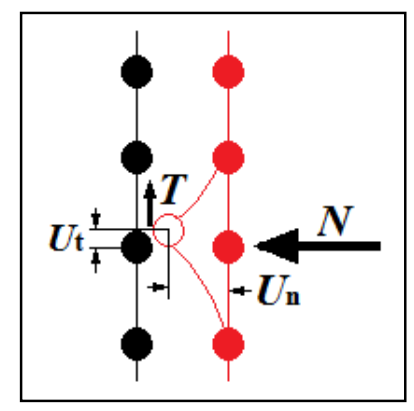

Figure 7 - Contact at interfaces. 


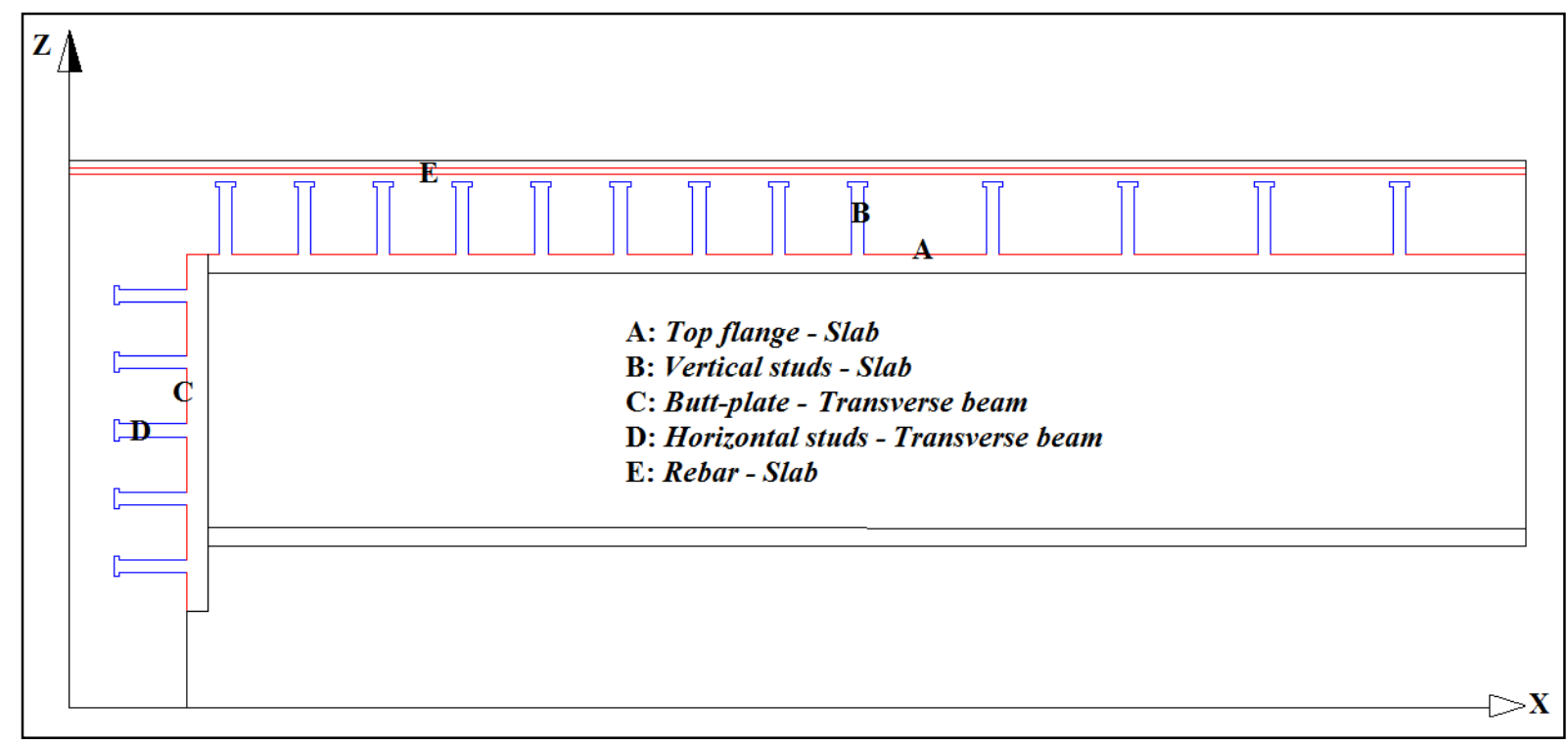

Figure 8 - Contact-friction interfaces.

\section{MODEL CALIBRATION}

As shown previously in Section 2 and Figure 3, the experimental test begins by a cyclic loading procedure. Even if the number of loading cycles and their magnitude remain in the elastic domain, micro-cracks were observed on the top of the zone of the slab called Slab1. In order to take into account this pre-loading effect in the numerical model, the concrete mechanical behaviour must be well-calibrated.

The calibration must approach as close as possible the real behaviour of the specimen during this pre-loading stage. After this stage, at the beginning of the monotonic loading, the microcracks could be supposed closed and the material recover its original stiffness.

A parabolic decreasing of the mechanical parameters of the slab (Figure 9) is adopted in this work using a penalty factor $\rho$ that multiplies the Young's modulus as well as the yield stress of the concrete slab. Since the cracks disappear at the end of the Slab1, the penalty factor becomes equal to 1 .

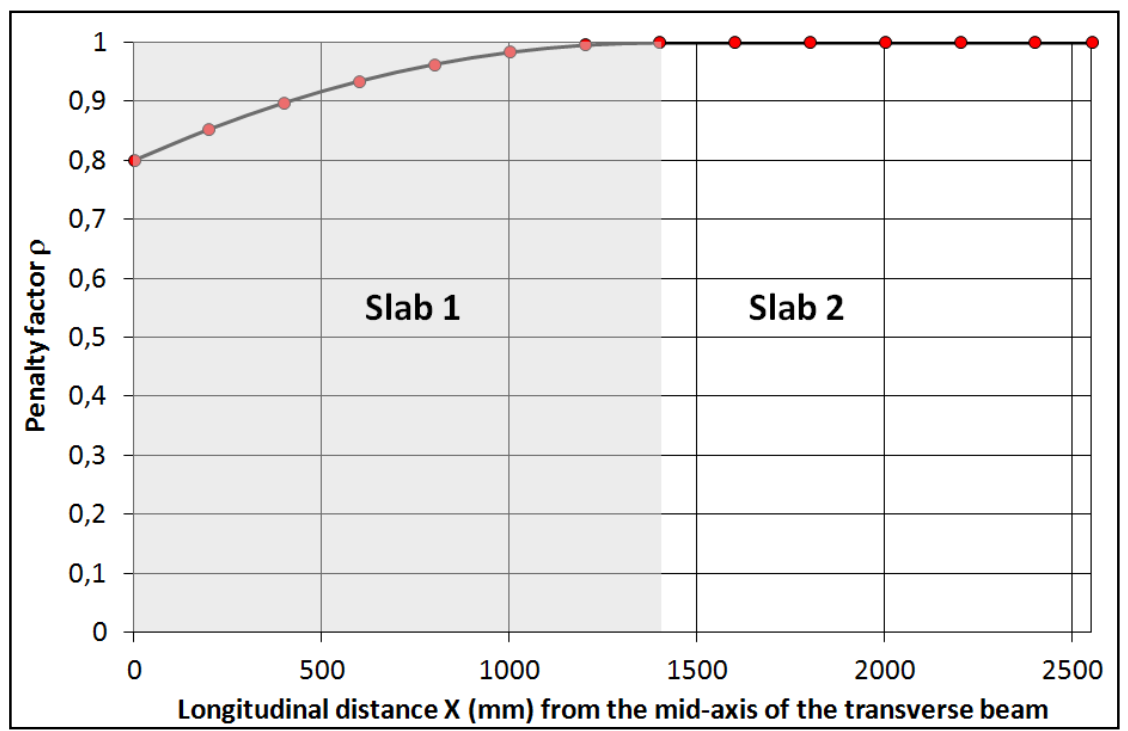

Figure 9 - Calibration of mechanical parameters for the concrete slab. 
The assumption/simplification of the cracking of the concrete has an important effect especially for the initial stiffness slop of the joint behaviour. It is pointed out that this assumption/simplification is based on a numerical calibration. Figure 9 shows that penalty factor $\rho$ that multiplies the Young's modulus as well as the yield stress of the concrete slab is fixed to 0.8 at the beginning (mid-axis of the transverse beam) and decreases to 1 at the midlength of the specimen (no micro-cracks observed at this distance at the end of the cyclic preloading). The parabolic decreasing of the penalty factor remains a pure assumption but the value of 0.8 has been obtained after several numerical simulations with the principal criterion is to have the numerical curve as-close-as possible to the envelop of the experimental measurements on concerned distance.

First comparison between numerical and experimental results concerns the $(F-\delta)$ curve at the end of the specimen. It appears in Figure 10 that the model gives accurate results. The penalty factor $\rho$ has been calibrated in order to best fit the envelope curve of the experimental load-displacement curve.

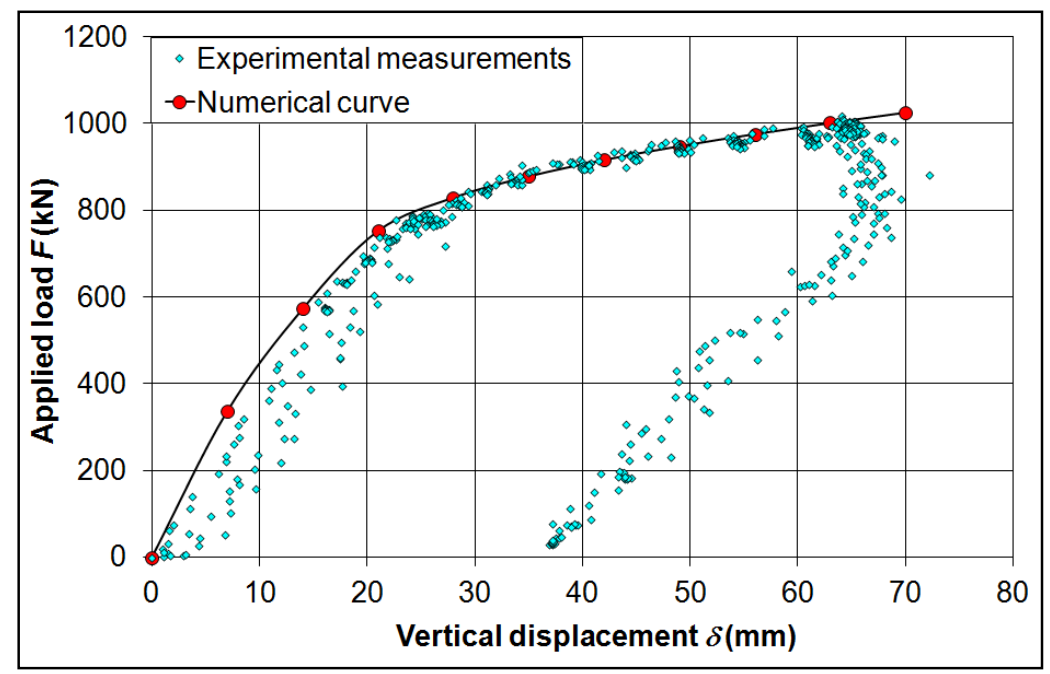

Figure 10 - Comparison of the (load-displacement) results at the end of the specimen.

The comparison between numerical and experimental results of the vertical stud slip and the butt-plate horizontal displacements concerns 3 loading stages: $200 \mathrm{kN}, 600 \mathrm{kN}$ and $900 \mathrm{kN}$. Figure 11 shows the stud slip variation along longitudinal $\mathrm{X}$-axis of the specimen obtained by the numerical model and compared against the experimental measurements. Considering the low slip values (both measured experimentally and determined numerically) the obtained results can be estimated as satisfactory. The general shape of the slip distribution observed experimentally has been well found numerically. In the parametric study that follows this model calibration, the Slab1 as-well-as the Slab2 will be considered without cracks (no cyclic pre-loading for the specimen). Figure 12 shows the horizontal displacements of the butt-plate. The model gives a relatively good representation of the horizontal displacements over the butt-plate height except at the top of the butt-plate where the displacements are overestimated (which is consistent with the above slip results of the model). It is pointed out that the rotation center $R$ of the butt-plate is at the same location for both numerical and experimental curves. 


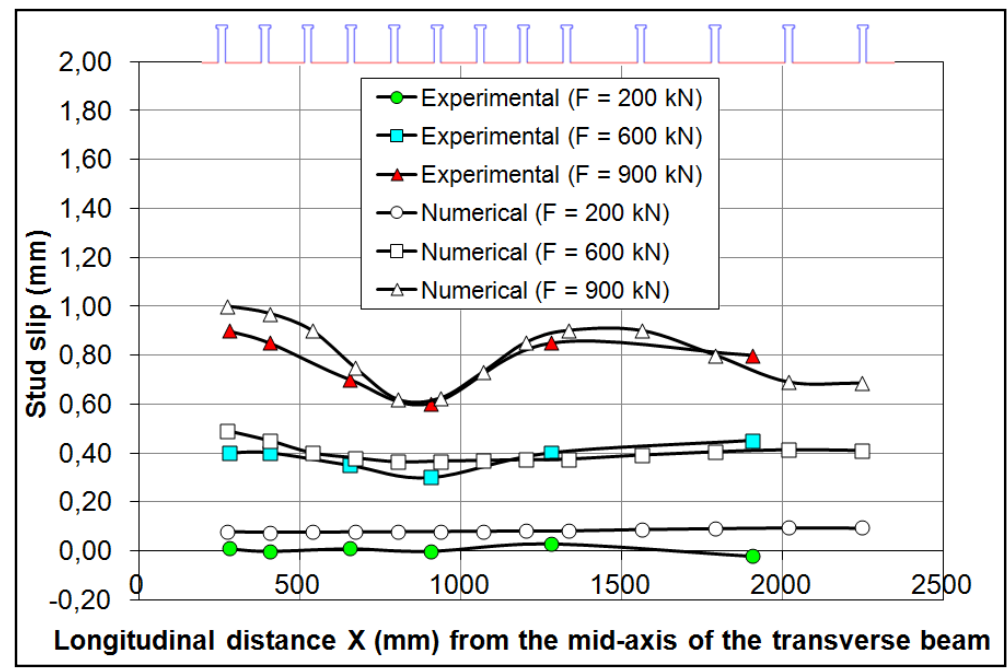

Figure 11 - Comparison of the slab stud slip.

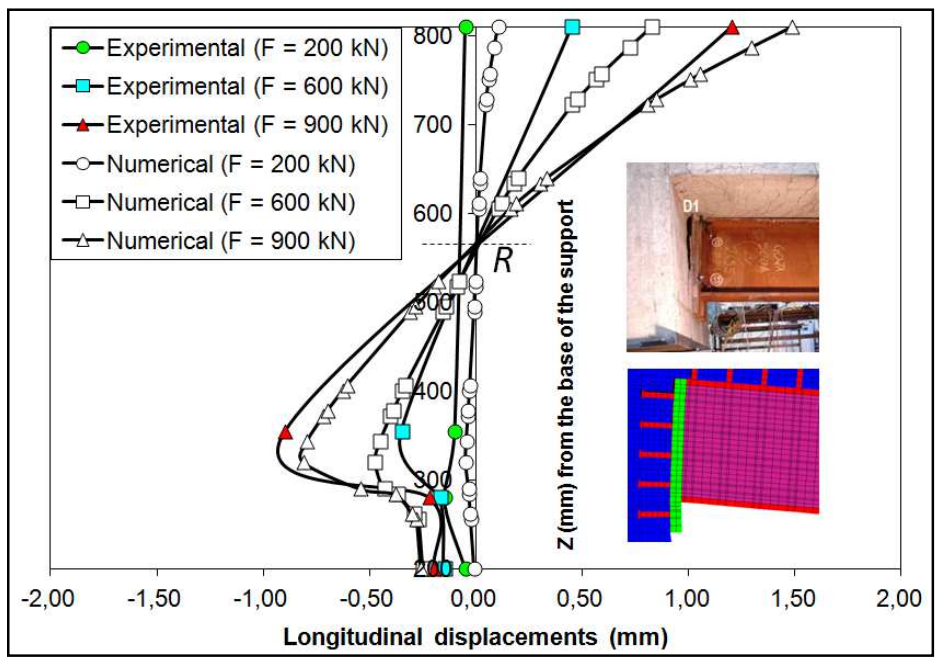

Figure 12 - Comparison of the butt-plate horizontal displacements.

\section{RECOVERING LONGITUDINAL STRESS MAGNITUDE IN THE SLAB REBARS}

In order to complete the model calibration made in the previous Section 3, a checking of the capacity of the 2D developed model to provide significant stress results has been undertaken in this Section 4. Such a comparison is possible in the case of slab rebars, insofar as the calculated stresses are simply axial and where the EN1994-1-1 [20] provides a simple analytical model. The butt-plate thickness considered in this Section is equal to $45 \mathrm{~mm}$.

The tensile stress magnitude in the rebar (1.93E+05 $\mathrm{MPa}$ - Figure 13) given by the numerical $2 \mathrm{D}$ model must be modified to recover the real stress value of the actual 3D problem. This post-treatment consists in dividing the calculated value by appropriate width $Y_{h}$ (Table 3 ) in accordance with the corresponding zone. It is clear that the post-treated stress so calculated will correspond to the actual 3D model but in homogenized configuration. 


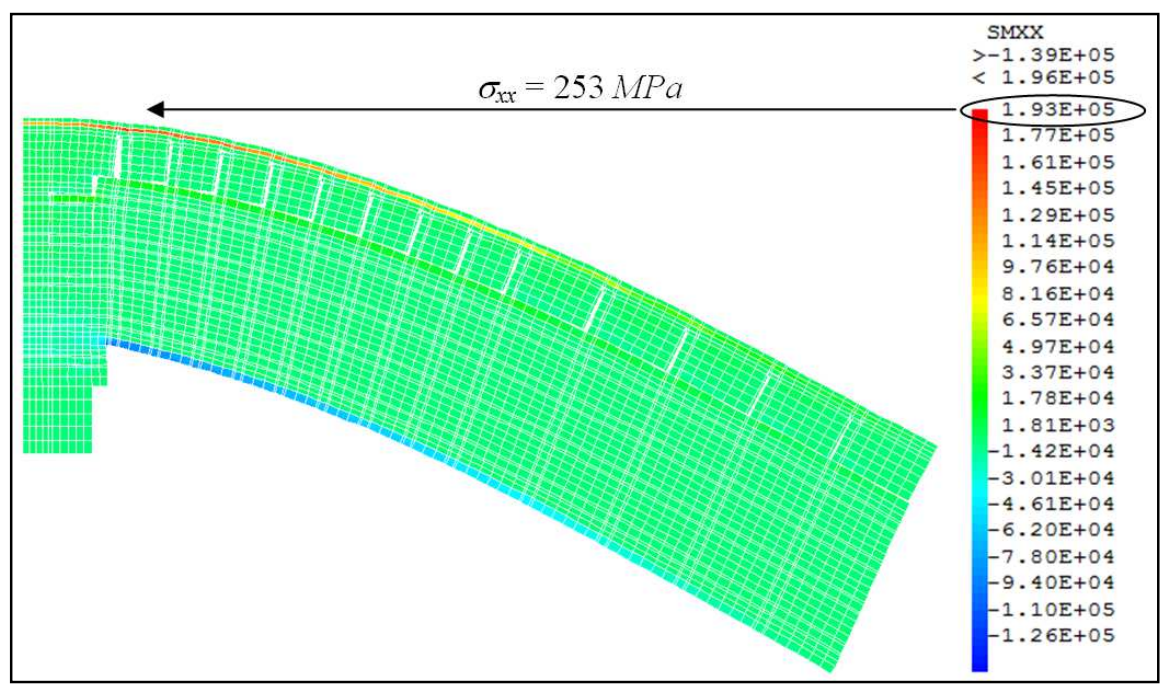

Figure 13 - Longitudinal stress $\sigma_{x x}$ for $F=600 \mathrm{kN}$.

Referring to Table 3, the equivalent homogenized material depth $Y_{h}$ is equal to $764 \mathrm{~mm}$ because this part of the rebar has same characteristics than those of "Zone J" in Table 3. The magnitude of the tension in the rebar obtained by the numerical model for $F=600 \mathrm{kN}$ is:

$$
\sigma_{s}^{(\text {num })}=\frac{1.93 E+05}{764}=253 \mathrm{MPa}
$$

For the analytical model, the rebar vertical position $Z^{(\text {num) }}$ (Figure 14) is equal to:

$$
Z_{s}^{(\text {num })}=h_{a}+\left(h_{c}+h_{s c}\right) / 2=490+(160+125) / 2=633 \mathrm{~mm}
$$

If one considers that the area of the rebar in Slab1 is: $A_{s}=6835.2 \mathrm{~mm}^{2}$, the neutral axis position is:

$$
Z_{a s}=\frac{Z_{a} A_{a}+Z_{s}^{(\text {num })} A_{s}}{A_{a}+A_{s}}=\frac{(490 / 2) \times 19750+633 \times 6835.2}{19750+6835.2}=344.8 \mathrm{~mm}
$$

where $Z_{a}=h_{a} / 2$ is the centroïd position of the steel cross-section and $A_{a}$ its area.

An analytical calculation of the tensile stress in the rebar gives:

$$
\sigma_{s}^{(\text {ana })}=\frac{M_{E d}\left(Z_{s}^{(\text {num })}-Z_{a s}\right)}{I_{2}}=\frac{600 \times 2.3 \times 10^{6}(633-344.8)}{1473242000}=270 \mathrm{MPa}
$$

where $M_{E d}=F \times d$ ( with: $F=600 \mathrm{kN}$ and $d=2.3 \mathrm{~m}$ is the distance from the applied load to the concerned cross-section). $I_{2}$ is the second moment of area of the effective equivalent section neglecting concrete in tension but including reinforcement.

Compared to the numerical value $\sigma_{s}^{(\text {num })}=253 \mathrm{MPa}$, the analytical elastic value $\sigma_{s}^{(a n a)}=270 M P a$ is larger. This result is not surprising if one considers that the analytical calculated value results of the simplifying assumptions of the beam theory and consequently does not take into account the interface interactions as slip, friction..., as is the case in the numerical calculation. 
In order to underline that the bending moment corresponding to the load $F=600 \mathrm{kN}$ considered in the above calculations is close to the elastic bending moment $M_{e l, R d}$, a simple elastic calculation shows that the elastic hogging bending is obtained when the yield stress is reached at the bottom flange of the steel beam $\left(\sigma_{a, b}=f_{y, a}\right)$; in this case we have: $M_{e l, R d}=-$ $1461 \mathrm{kNm}$ and the corresponding load is $F=635 \mathrm{kN}$.

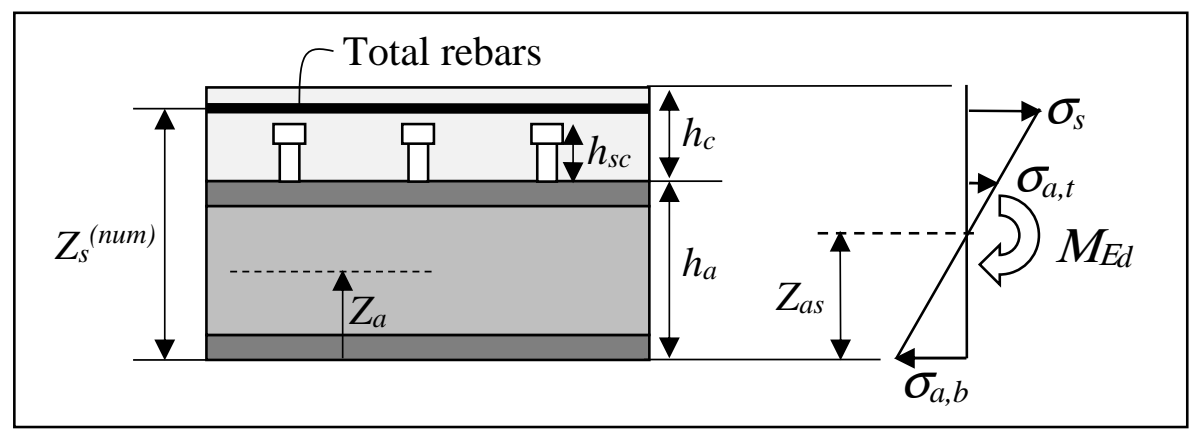

Figure 14 - Elastic hogging bending.

\section{BUTT-PLATE THICKNESS INFLUENCE}

As mentioned in the introduction, to illustrate the performances of the $2 \mathrm{D}$ model, the example of the parametric study of the influence of the variation of the butt-plate thickness was chosen. Indeed, the butt-plate thickness is one of the most influential parameters on the behaviour of the type of joint under investigation in this paper. Keeping the same geometrical and mechanical characteristics of the experimental specimen, the thickness of the butt-plate is varied, starting from $20 \mathrm{~mm}$ (the lowest possible thickness in our case regarding welding possibilities) to $60 \mathrm{~mm}$, considering a $10 \mathrm{~mm}$ increase between two consecutive thicknesses.

\subsection{Plot principal stresses}

The same post-treatment described in Section 4 is applied to the principal stresses obtained by the simplified 2D model.

In Figures $(15,16$ and 17) are plotted the maximum principal stresses with regard to the buttplate thickness for the steel beam flanges, the butt-plate and the horizontal stud anchors respectively. Three loadings have been considered: an initial loading of $200 \mathrm{kN}$, a loading of $600 \mathrm{kN}$ near the serviceability state and a loading of $900 \mathrm{kN}$ close to the ultimate state.

The increasing of the butt-plate thickness leads to following remarks:

- A slight increase of the compressive stresses transmitted by the lower beam flange when the butt-plate thickness increases from $20 \mathrm{~mm}$ to $40 \mathrm{~mm}$ and a more significant increase of the tensile stresses transmitted by the upper beam flange when the butt-plate thickness increases from $20 \mathrm{~mm}$ to $60 \mathrm{~mm}$ (Figure 15).

- Tensile and compressive stresses in butt-plates decrease significantly (Figure 16). Maximum values are located at the welding with the top stud-row for tension and at the welding with the bottom steel beam flange for compression.

- A slight increase of the maximum tensile stresses is observed at the top stud anchor row of the butt-plate and conversely a slight decrease of the maximum compressive stresses at the bottom stud anchor row of the butt-plate (Figure 17). 


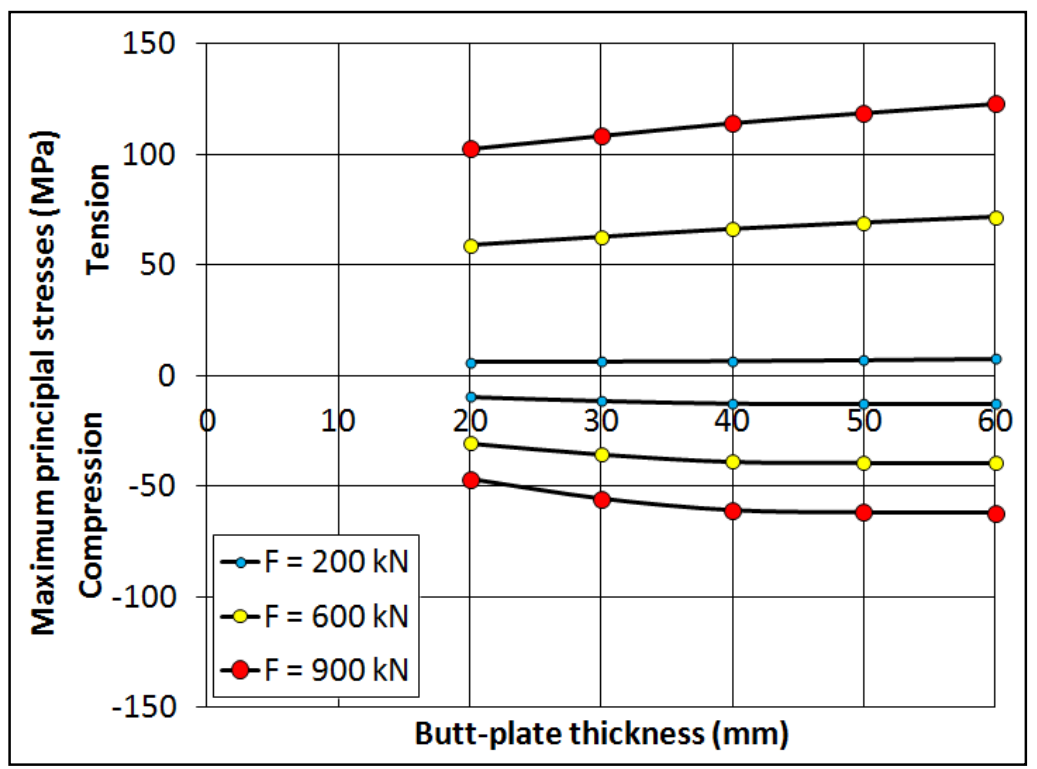

Figure 15 - Maximum principal stresses in steel beam flanges.

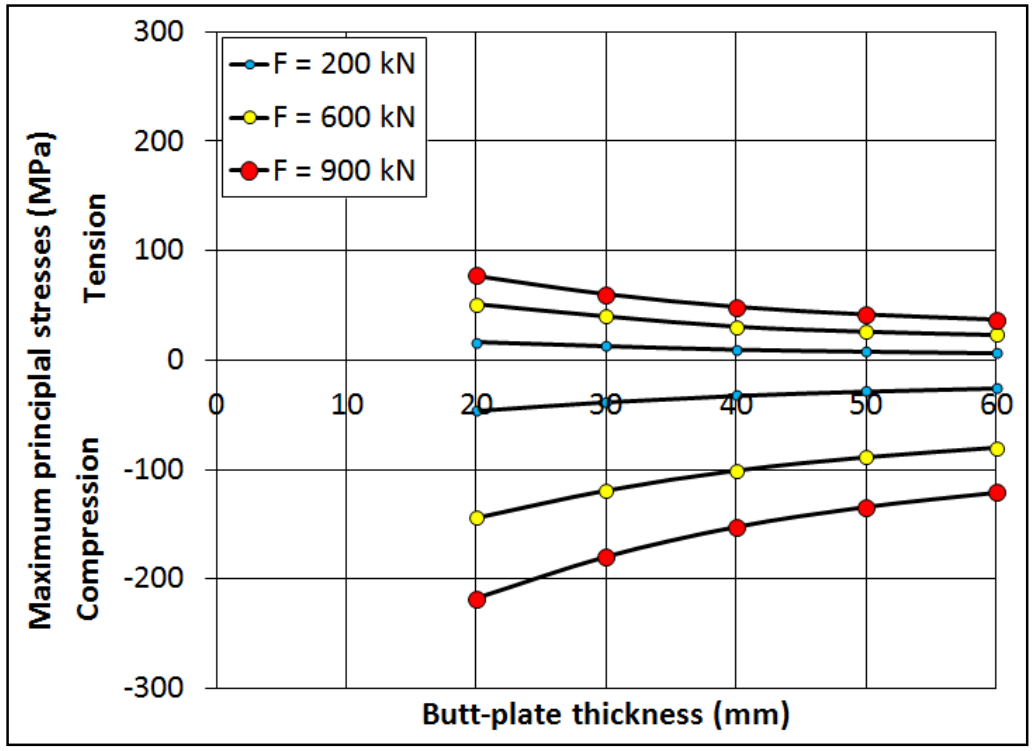

Figure 16 - Maximum principal stresses in butt-plate. 


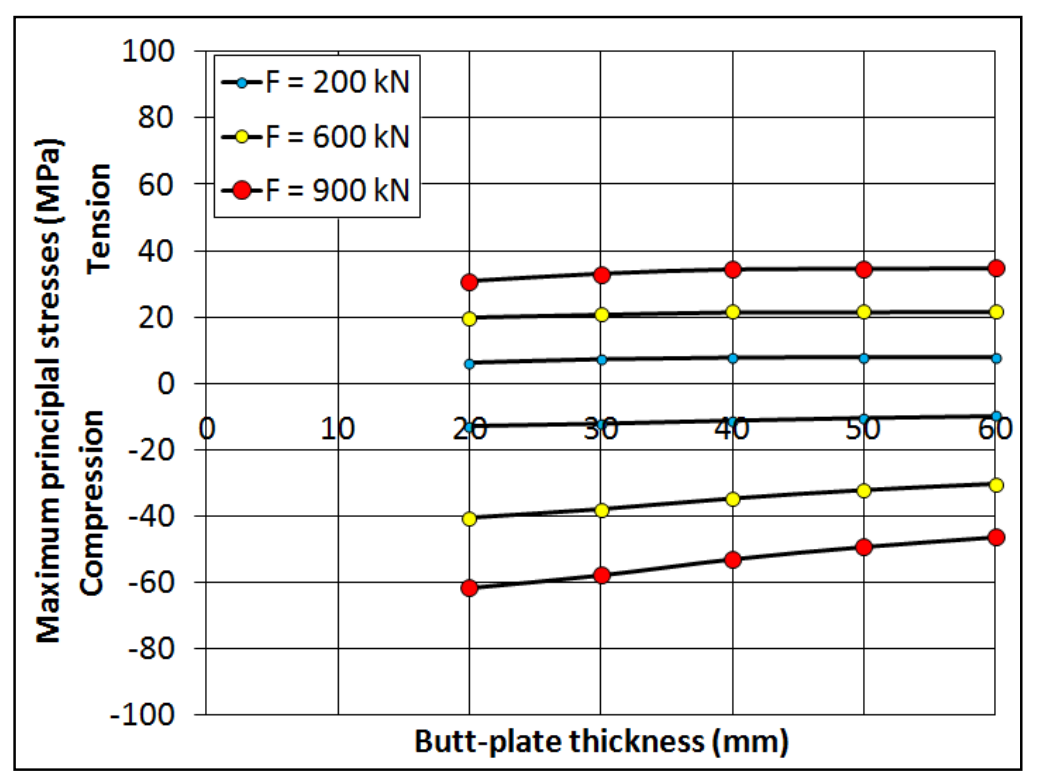

Figure 17 - Maximum principal stresses in horizontal stud anchors.

\subsection{Plot longitudinal stresses}

Concerning maximum tensile and compressive stresses in the web and in the transverse concrete beam, the interest was focused on the variation of the longitudinal stress $\sigma_{\mathrm{xx}}$ along the lines $(\mathrm{W})$ for the web of the steel beam and $(\mathrm{T})$ for the transverse concrete beam (Figure 18). The stresses obtained by the proposed 2D-model have been divided by corresponding depths according to Table $3\left(Y_{h}=12 \mathrm{~mm}\right.$ for the web and $Y_{h}=688 \mathrm{~mm}$ for the transverse beam).

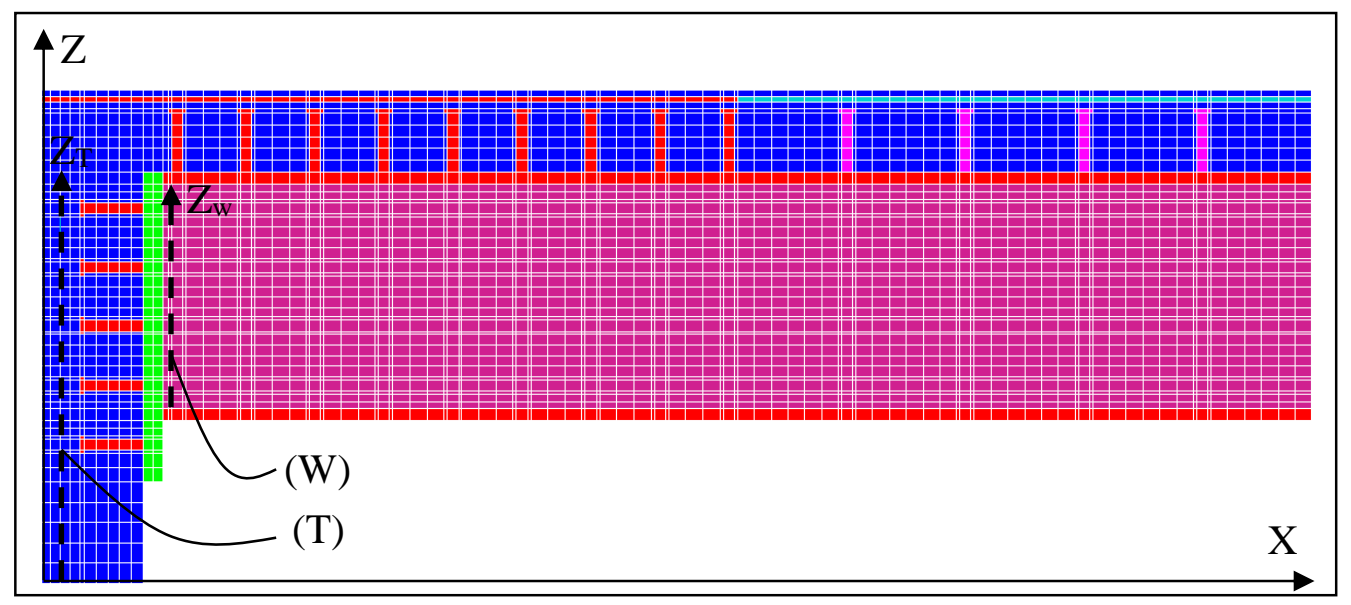

Figure 18 - Lines (W) and (T) for stress plots.

- In Figures 19 (dealing with the line (W) defined in Figure 18 by the axis $\mathrm{Z}_{\mathrm{w}}$ whose origin is located at the bottom of the steel beam web), the increase of the butt-plate thickness significantly reduces maximum tensile stresses at the top of the web more than the compression at the bottom. As can be seen, the stress distribution is not symmetric with a compression zone significantly larger than the tension one. A tensile stress peak appears at the level of the upper stud row whereas a quasi linear compressive stress distribution is observed. After a small decreasing of the position of the neutral axis at the beginning of the loading, the neutral axis remains in a fixed position of the steel girder web. With the increase of the buttplate thickness a decreasing of the maximum tensile stress in the web of the steel beam is observed. For example, when the butt-plate thickness increases from $20 \mathrm{~mm}$ to $60 \mathrm{~mm}$, the 
decreasing of the maximum tensile stress is $66 \%$ for $F=200 \mathrm{kN}, 58 \%$ for $F=600 \mathrm{kN}$ and $36 \%$ for $F=900 \mathrm{kN}$. In compression zone, the decreasing of the maximum compressive stress in the web of the steel beam is only $12 \%, 10 \%$ and $8 \%$ for same load levels, respectively.

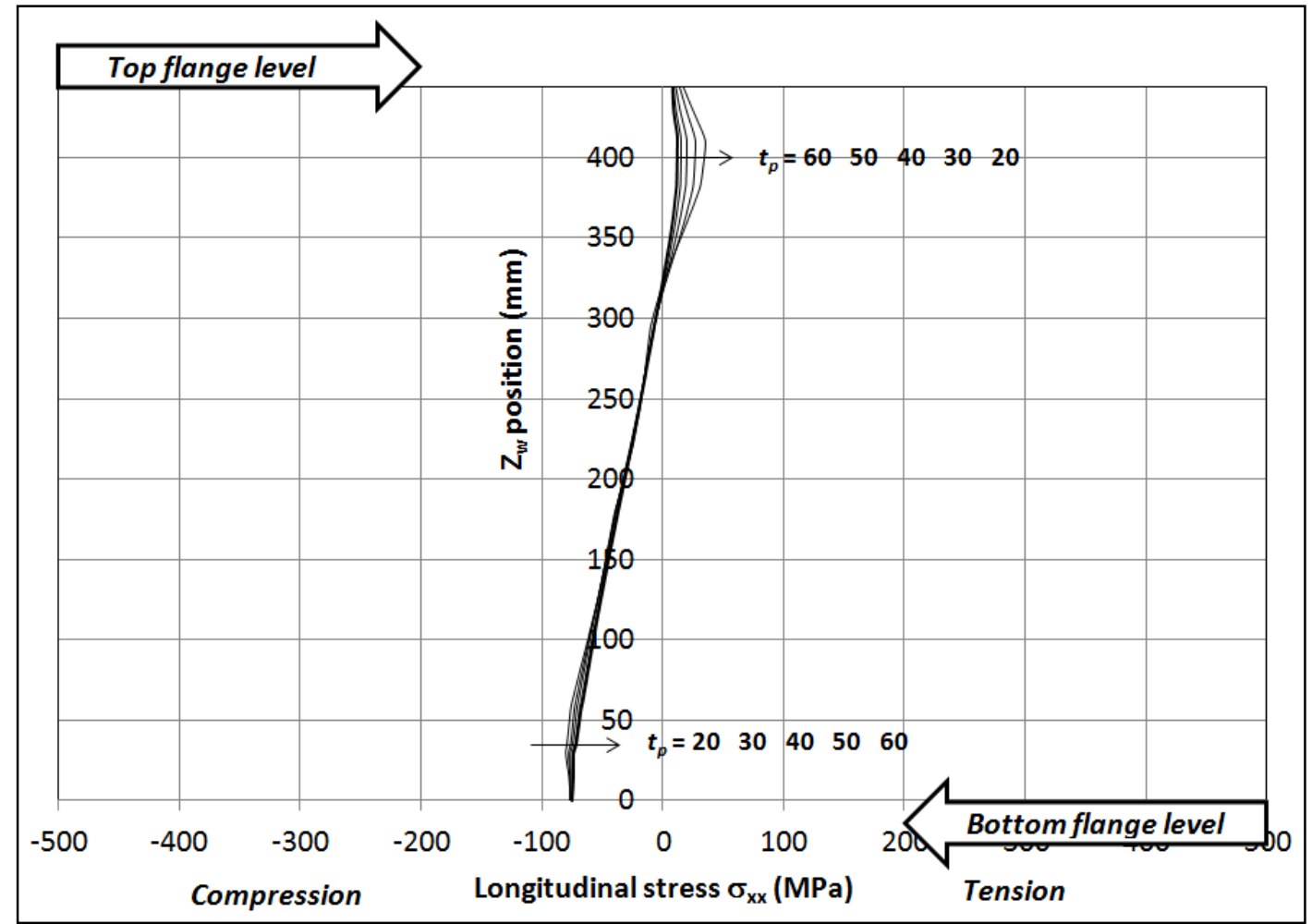

Figure 19.a - Butt-plate thickness influence on the web longitudinal stresses (Line W - Figure 18) $-F=200 k N$.

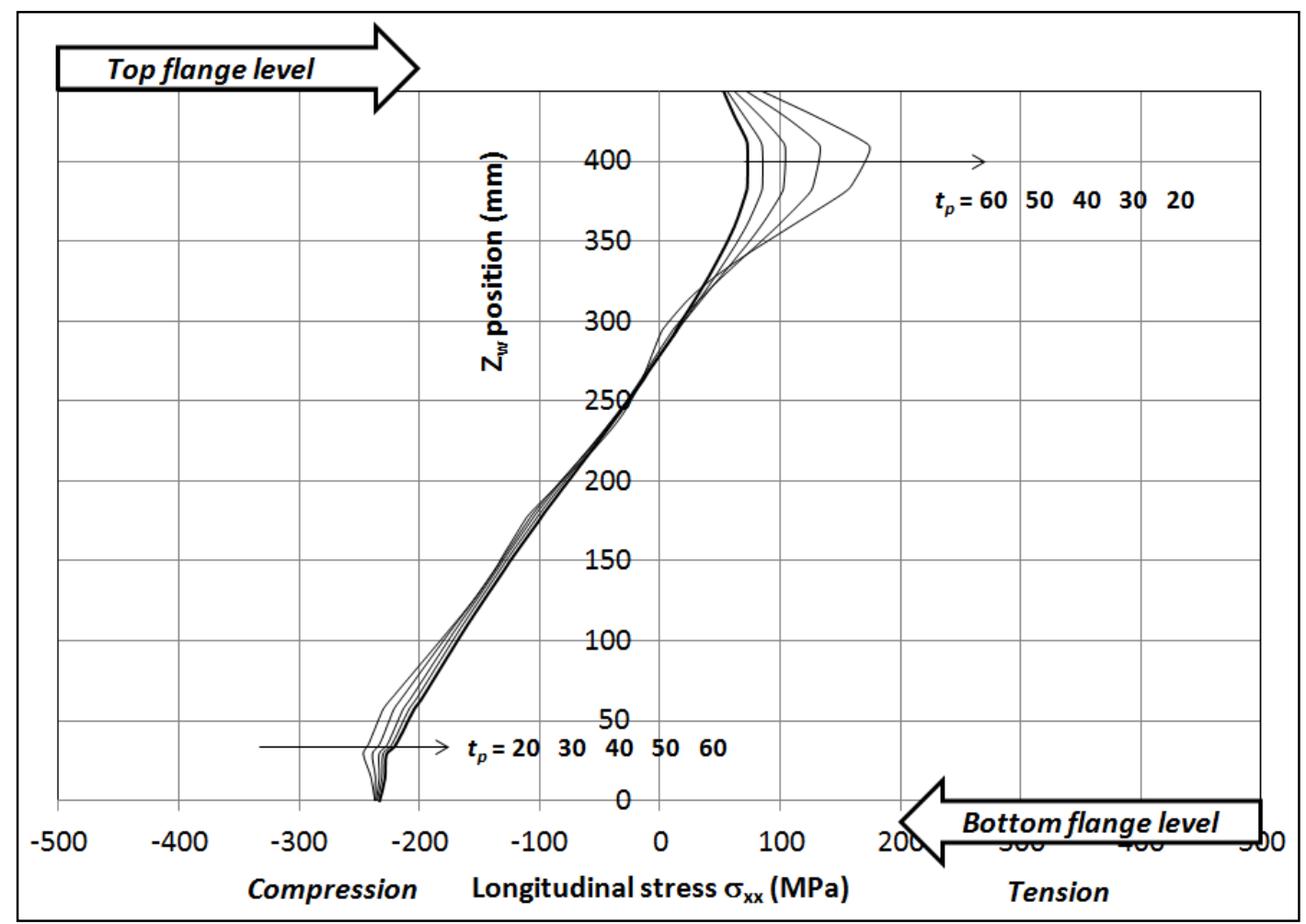

Figure 19.b - Butt-plate thickness influence on the web longitudinal stresses 
(Line $\mathrm{W}-$ Figure 18) $-F=600 \mathrm{kN}$.

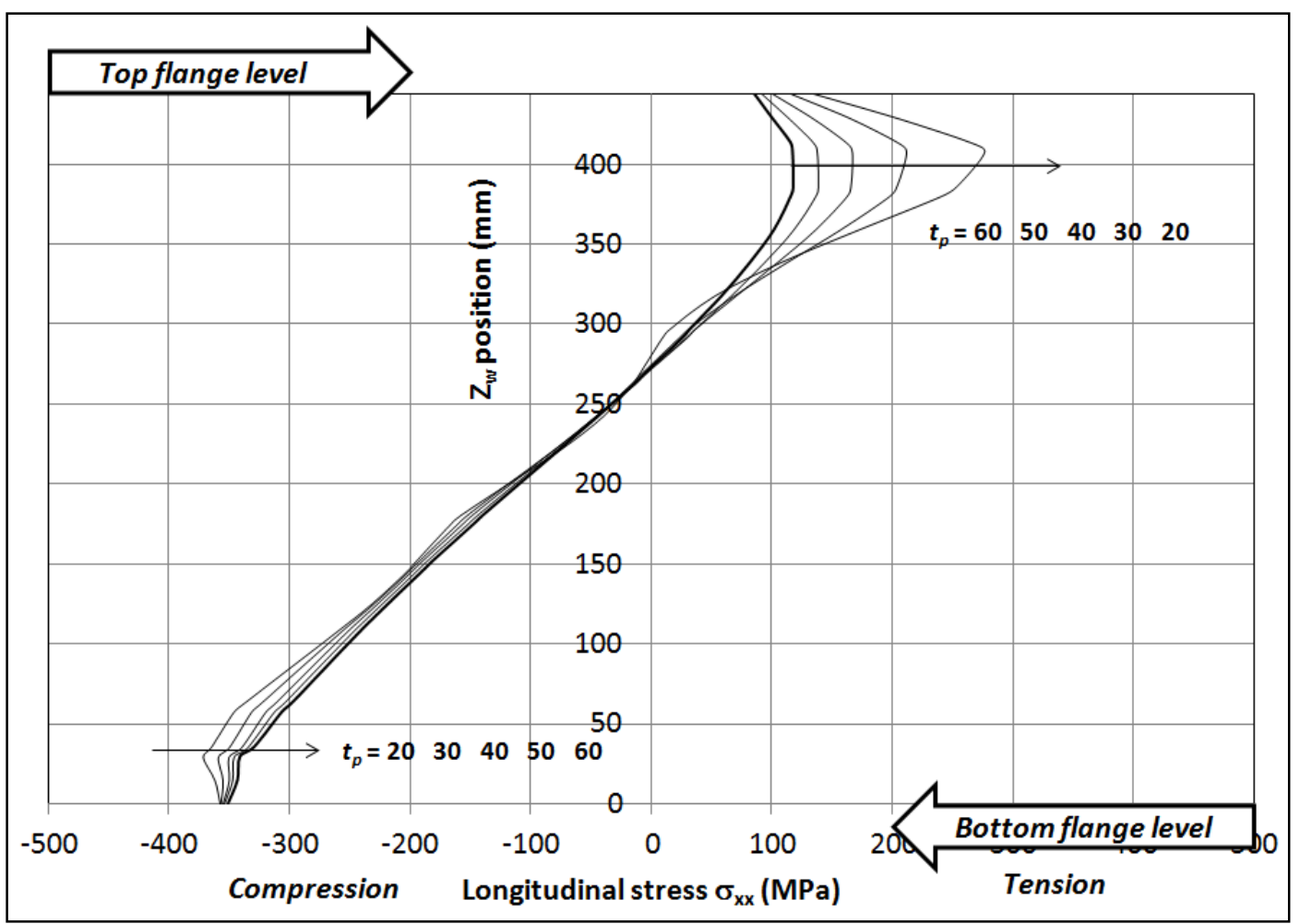

Figure 19.c - Butt-plate thickness influence on the web longitudinal stresses (Line W - Figure 18) $-F=900 k N$.

- In Figures 20 (concerning line $(\mathrm{T})$ defined in Figure 18 by the axis $\mathrm{Z}_{\mathrm{T}}$ whose origin is located at the bottom of the transverse concrete beam), it can be observed that the increase of the butt-plate thickness significantly increases maximum tensile stresses at the top of the transverse concrete beam and in equivalent ratio it reduces the compressive stresses at the bottom flange level. Comparing maximum stresses obtained for $20 \mathrm{~mm}$ and $60 \mathrm{~mm}$ butt-plate thicknesses, respectively, the increase of the tensile stresses is around $50 \%$ for both $F=600$ $k N$ and $F=900 \mathrm{kN}$ while compressive stresses reduce of about $26 \%$. 


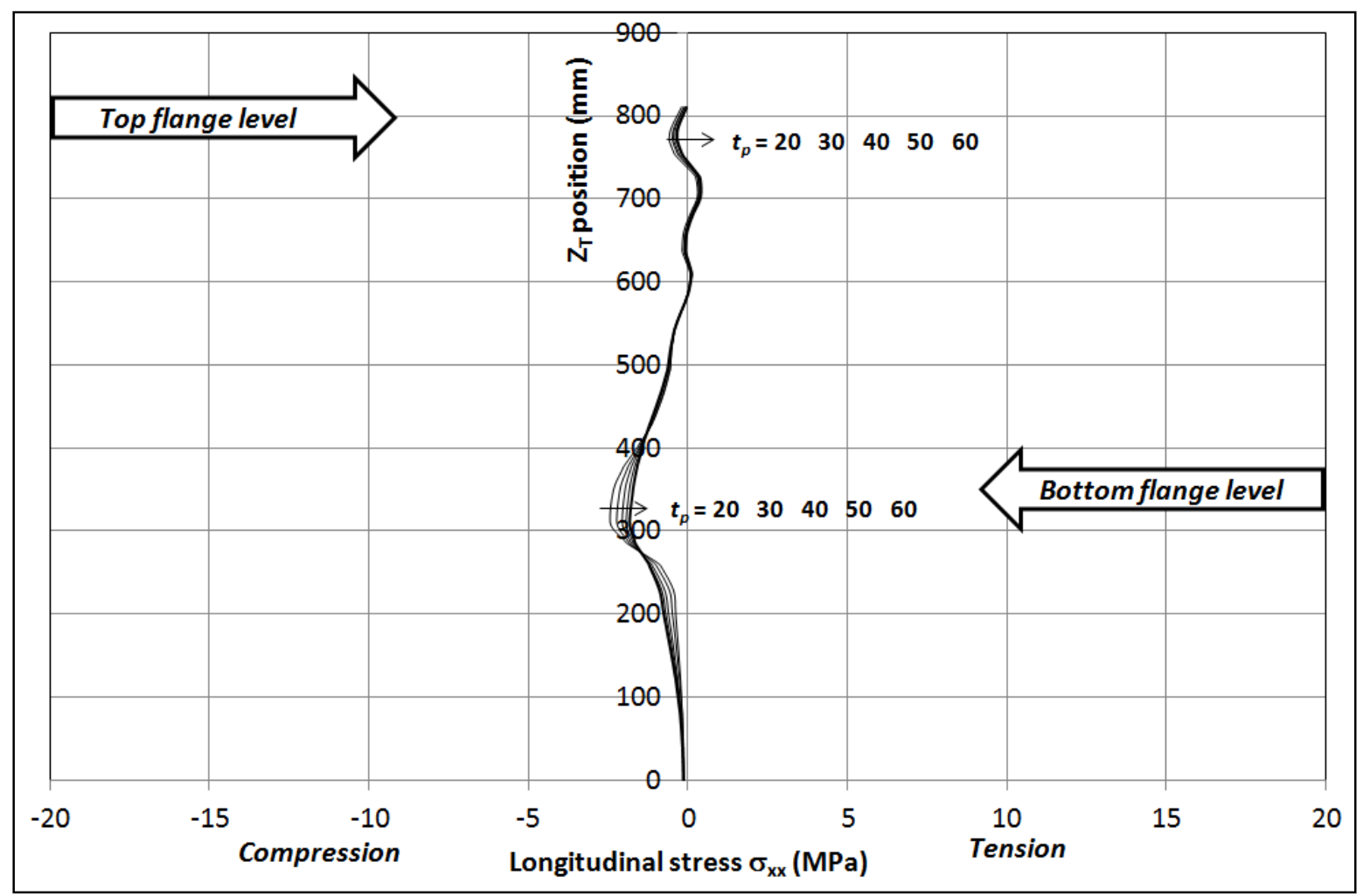

Figure 20.a - Butt-plate thickness influence on longitudinal stresses of the transverse beam (Line T - Figure 18) $-F=200 k N$.

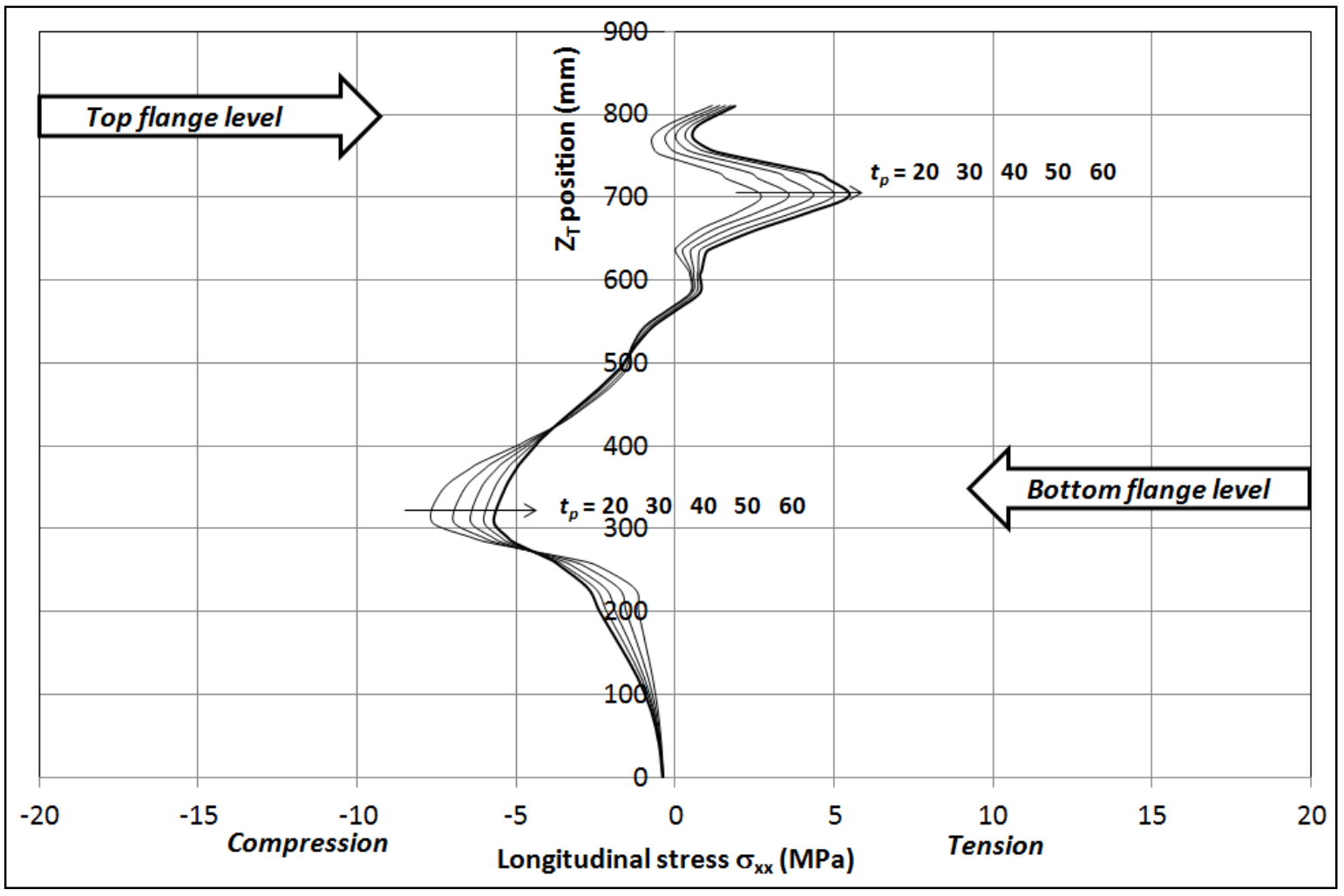

Figure 20.b - Butt-plate thickness influence on longitudinal stresses of the transverse beam (Line T - Figure 18) $-F=600 \mathrm{kN}$. 


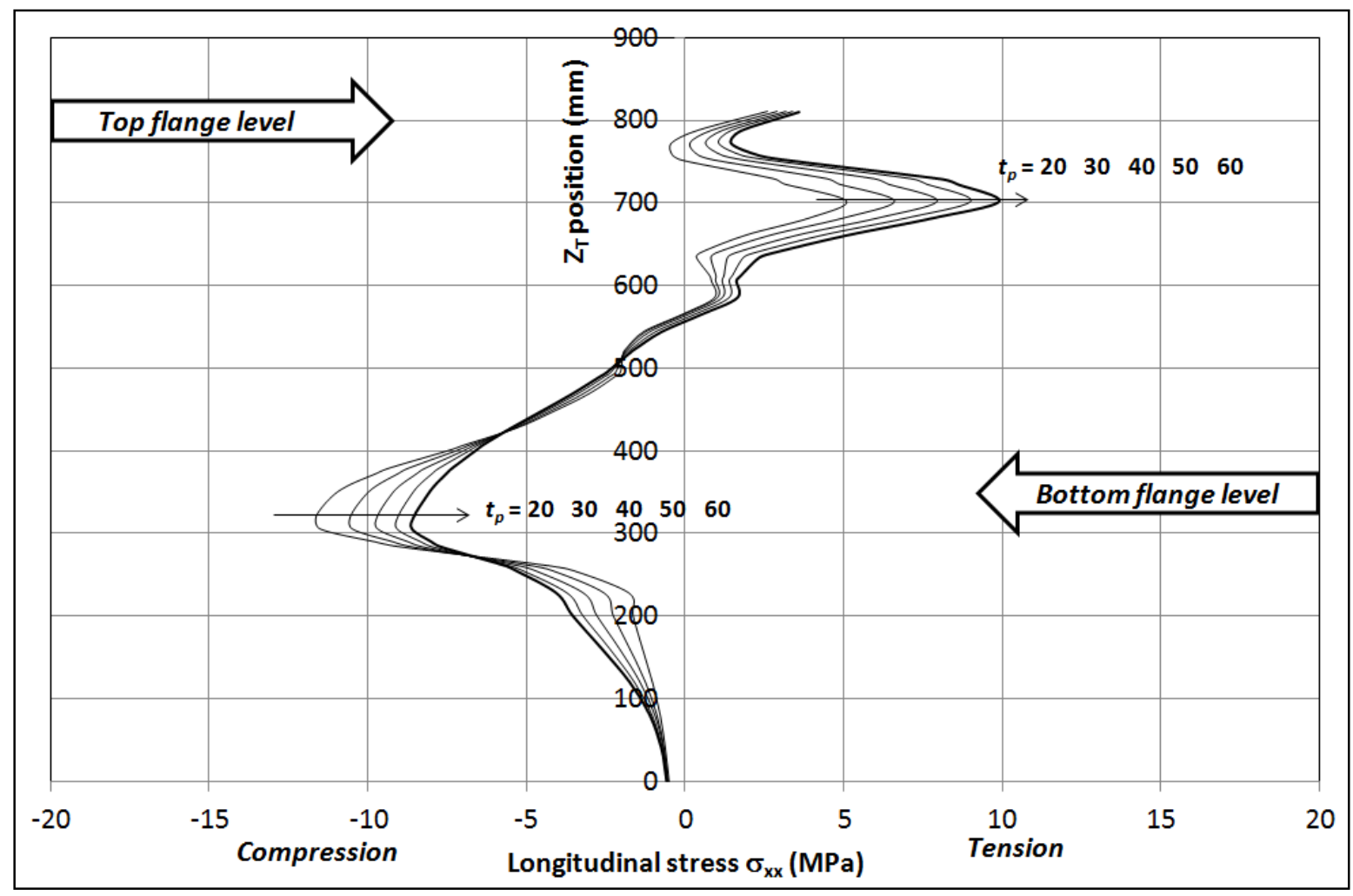

Figure 20.c - Butt-plate thickness influence on longitudinal stress of the transverse beam (Line T - Figure 18) $-F=900 k N$.

In conclusion of this Section, it appears that a thinner thickness of the butt-plate may lead to higher compressive stresses in the transverse beam. However, a thicker thickness of the buttplate tends to increase tensile stresses in the transverse beam and in the beam flange. So, it seems that the choice of an intermediate thickness is the better solution. This conclusion confirms the choice of a thickness of $45 \mathrm{~mm}$ made for the design of the test specimen presented in Section 2. A same thickness of $45 \mathrm{~mm}$ was retained in the presentation of Sections 4 and 6.

\section{FORCE-TRANSFER MECHANISM}

Previous investigation leads to pay an attention to the force-transfer mechanism towards the joint. In Figures 21 are plotted the principal stresses over the whole specimen for a butt-plate thickness equal to $45 \mathrm{~mm}$ and an applied load equal to $600 \mathrm{kN}$. Von-Mises stresses are also plotted in the same figures.

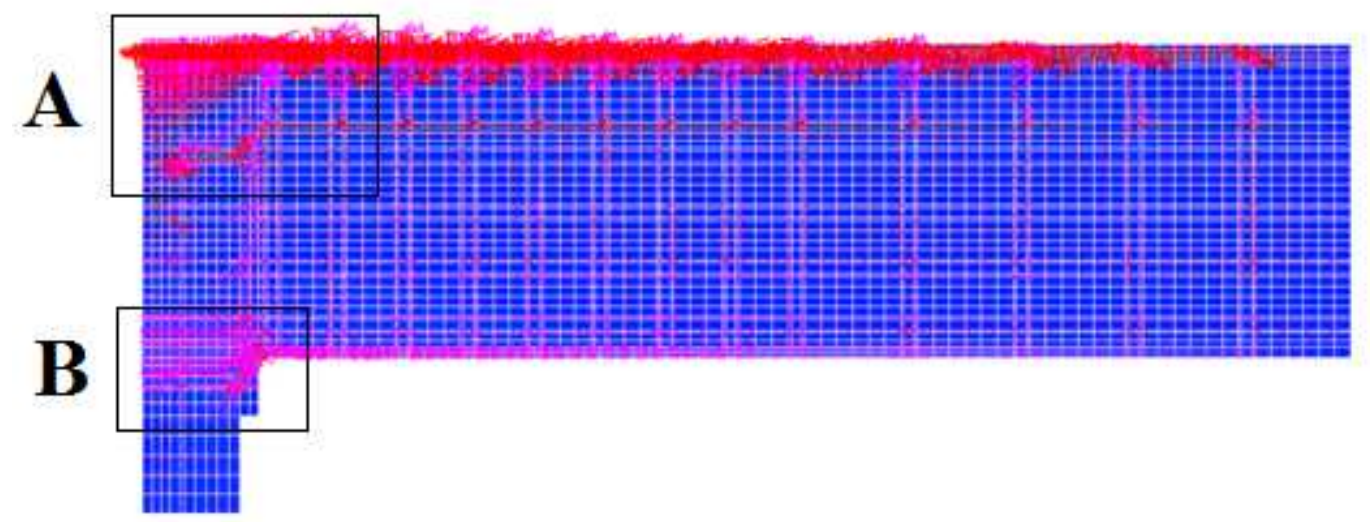




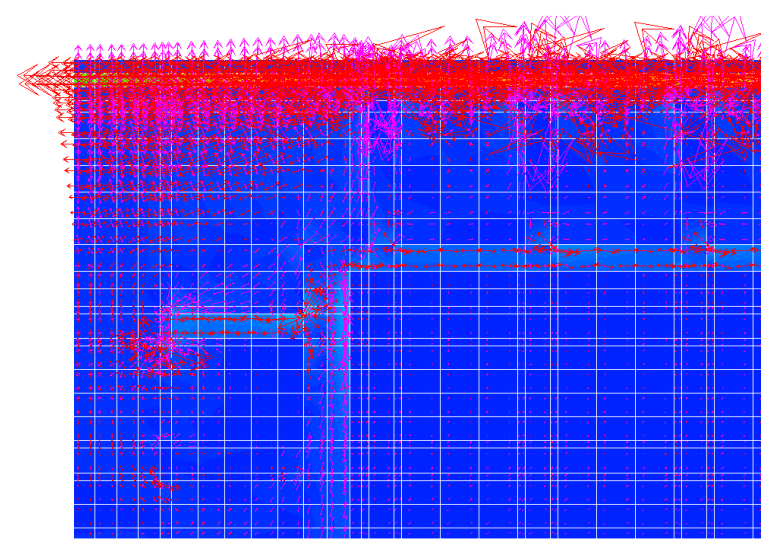

Zoom A

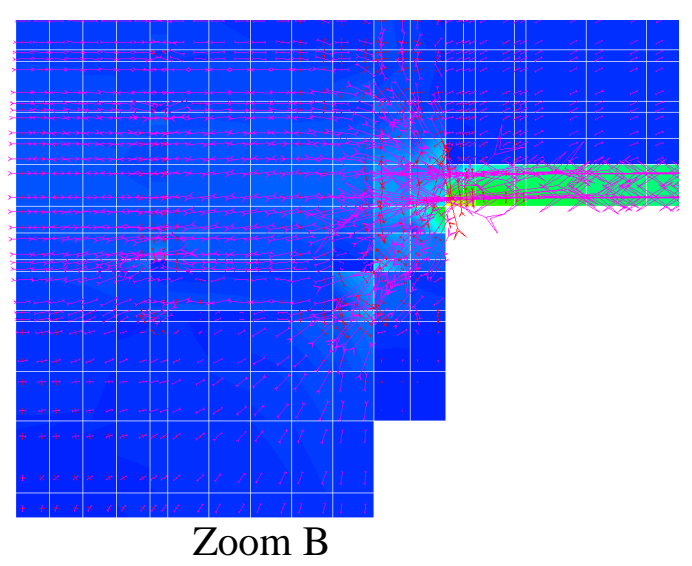

Figure 21 - Principal stresses in the specimen $(F=600 \mathrm{kN}$ - Butt-plate thickness $=45 \mathrm{~mm})$.

The internal forces transmitted by the composite beam cross-section close to the joint are: a vertical shear force $V_{E d}$ and a bending moment $M_{E d}$. In the joint, the hogging bending moment $M_{E d}$ is primarily transmitted by:

- Tensile force $F_{t, E d}$ in the longitudinal rebars of the slab;

- Compressive force $F_{c, E d}$ in the bottom flange of the steel girder.

Maximum tensile stresses are effectively observed in the longitudinal reinforcement near the joint (Zoom A - Figure 21) and maximum compressive stresses in the steel bottom flange (Zoom B - Figure 21).

In addition, internal additional forces $N_{a d}$ and $M_{a d}$ are also transmitted by the web fastening ensuring the global equilibrium of normal forces and bending moments of the joint crosssection.

The normal compressive force coming from the bottom-flange is firstly transmitted through the butt-plate to the transverse concrete beam. Stress diffusion through the butt-plate thickness is observed beginning from top and bottom welding points between the bottom flange and the butt-plate. The diffusion trough the butt-plate associated with an additional diffusion effect due to the bending of the butt-plate is essential to reduce the intensity of the compressive stress transmitted to the concrete of the transverse beam. The maximum compressive stress transmitted by the steel bottom flange is ( $54 \mathrm{MPa}$ for $F=200 \mathrm{kN}, 170 \mathrm{MPa}$ for $F=600 \mathrm{kN}$ and $258 \mathrm{MPa}$ for $F=900 \mathrm{kN}$ ). The maximum compressive stress in the transverse concrete beam is only ( $7 \mathrm{MPa}$ for $F=200 \mathrm{kN}, 22 \mathrm{MPa}$ for $F=600 \mathrm{kN}$ and $35 \mathrm{MPa}$ for $F=900 \mathrm{kN}$ ). These results are consistent with the additional bearing width $c$ introduced in Section 6.2 .5 of EN1993-1-8 (see Section 2.1 of this paper, Figure 5).

\section{1 - Tensile stresses in the slab rebars}

In order to highlight the influence of the percentage of longitudinal reinforcement in Slab1 and Slab2 on the force-transfer mechanism, the tensile stresses in the rebars are plotted in Figure 22 for each loading level $(F=200 \mathrm{kN}, F=600 \mathrm{kN}$ and $F=900 \mathrm{kN})$ in three different cases:

- Case 1 (Reinforced case): percentage of longitudinal reinforcement in Slab1: 2.67\% $\left(6835 \mathrm{~mm}^{2}\right)$ and in Slab2: $2.67 \%\left(6835 \mathrm{~mm}^{2}\right)$.

- Case 2 (Experimental case): percentage of longitudinal reinforcement in Slab1: $2.67 \%$ $\left(6835 \mathrm{~mm}^{2}\right)$ and in Slab2: 1.26\% (3226 $\left.\mathrm{mm}^{2}\right)$.

- Case 3 (Unreinforced case): percentage of longitudinal reinforcement in Slab1: 1.26\% $\left(3226 \mathrm{~mm}^{2}\right)$ and in Slab2: 1.26\% (3226 $\left.\mathrm{mm}^{2}\right)$. 
One reminds that the yield stress of the reinforcement is $f_{y, s}=585 \mathrm{MPa}$ and referring to Table 2, equivalent homogenized rebar depth $Y_{h}$ for Case 2 is equal to $764 \mathrm{~mm}$ in Slab1 and $510 \mathrm{~mm}$ in Slab2. The stresses obtained by the numerical model should be divided by these values in order to recover the real tensile stress in the rebar. Differently, all along the slab, for Case $1 Y_{h}$ $=764 \mathrm{~mm}$ and for Case $3, Y_{h}=510 \mathrm{~mm}$.

Even if it is clear that the number of studs in the slab should be in accordance with the percentage of rebars for a correct transmission of the effort at the interface between the slab and the steel girder, this simulation changes only the percentage of rebars and keeps all other parameters unchanged.

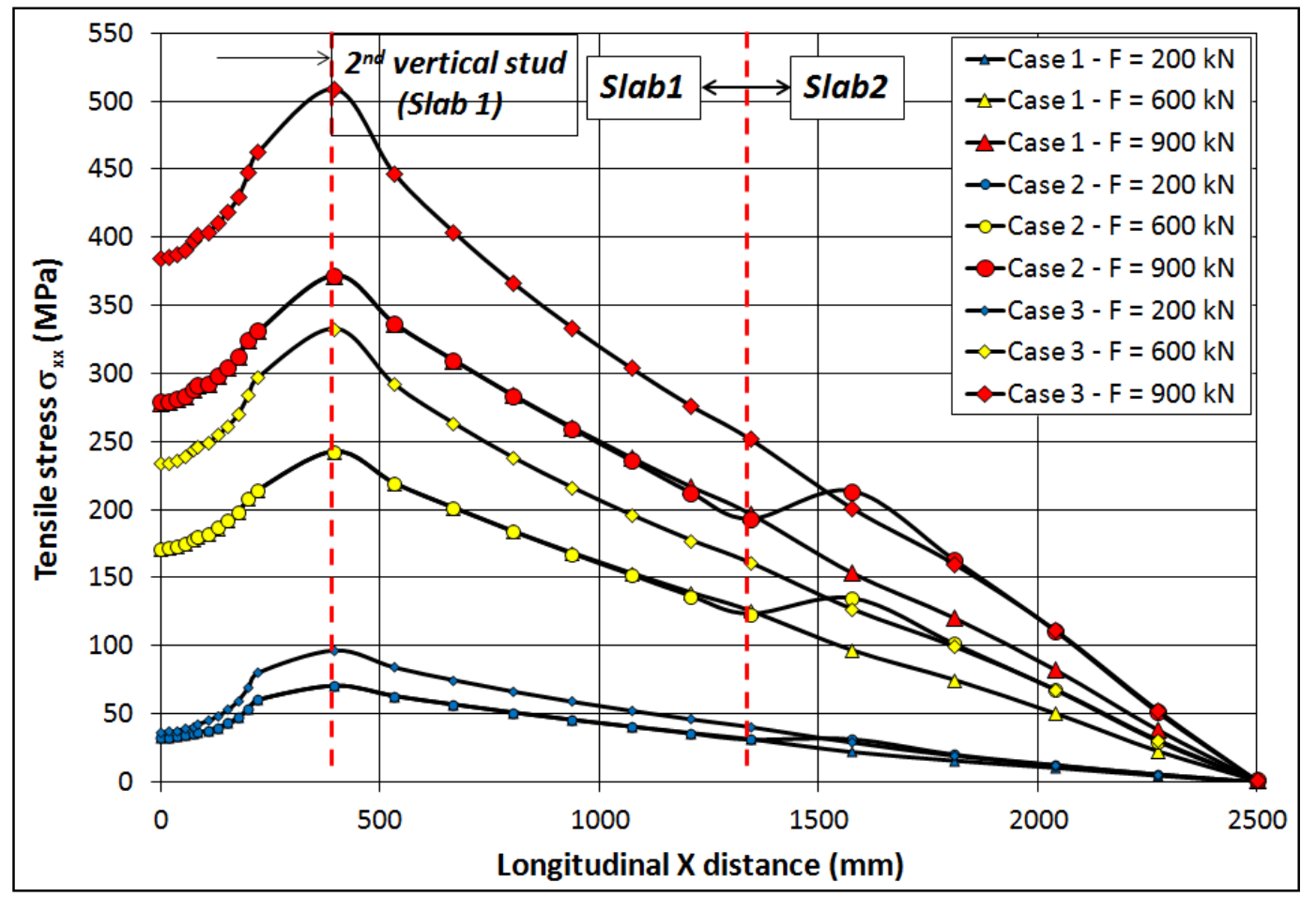

Figure 22 - Tensile stress in the rebar - Influence of the percentage of reinforcement.

One observes that:

- Whatever the case, maximum tensile stress is observed close the $2^{\text {nd }}$ vertical stud-row. In fact, this cross-section is close to the discontinuity between the butt-plate and the transverse beam. The cross-section located at the same X-position as the $1^{\text {st }}$ stud-row appears less stressed than the precedent one even if it is closer to the butt-plate. The experimental test results for $\mathrm{F}$ exceeding $900 \mathrm{kN}$ showed that the failure has been obtained at the $2^{\text {nd }}$ vertical stud-row which could confirm this numerical result. This slight shift of the critical crosssection is a real phenomenon to consider.

- Comparing Case 1 and Case 2, equivalent tensile stresses are observed in Slab1 because the same percentage of reinforcement is adopted. Nevertheless, in Slab2, the experimental test (Case 2) shows tensile stresses greater than the ones in Case 1 because the percentage of reinforcement decreases from $2.67 \%$ to $1.26 \%$. This increasing of the tension force is not detrimental in this area of the specimen (Slab2).

- In Case 3, the decreasing of the reinforcement to $1.26 \%$ all along the specimen leads to an important increasing of the stresses especially in Slab1 that could reach the yield stress for $F$ $=900 \mathrm{kN}$. 
This numerical simulation confirms the validity of the choice to vary the reinforcement of the specimen from Slab1 to Slab2 that has been adopted for the experimental test.

\section{2 - Longitudinal stresses in horizontal stud-rows}

In Figure 23, the longitudinal stress $\sigma_{\mathrm{xx}}$ at each horizontal stud-row and for each loading level $(F=200 \mathrm{kN}, F=600 \mathrm{kN}$ and $F=900 \mathrm{kN})$ and for the experimental specimen (Case 2 in Section 5.1) is plotted. It is pointed out that the numerical values obtained directly from the model are divided by corresponding depth $Y_{h}=176 \mathrm{~mm}$ (Table 3 - Material B). The tension from the top flange is mostly transmitted to the top studs and the compression (from the bottom flange) is mostly transmitted to the bottom studs. The internal studs do not support high stresses but are subjected to the effect of the web fastening (normal compression + bending moment) that give them low tension for some ones and compression for others. These results are consistent with those of Figures 20 ( $a, b$ and c) where longitudinal stresses in the transverse beam are shown. In Figure 23 (right hand) a zoom of the longitudinal stress $\sigma_{\mathrm{xx}}$ in the isolated system (Horizontal stud-rows + Butt-plate + Steel beam) is also presented. One observes that the butt-plate deformation is in accordance with the curves presented in the same figure (left side).

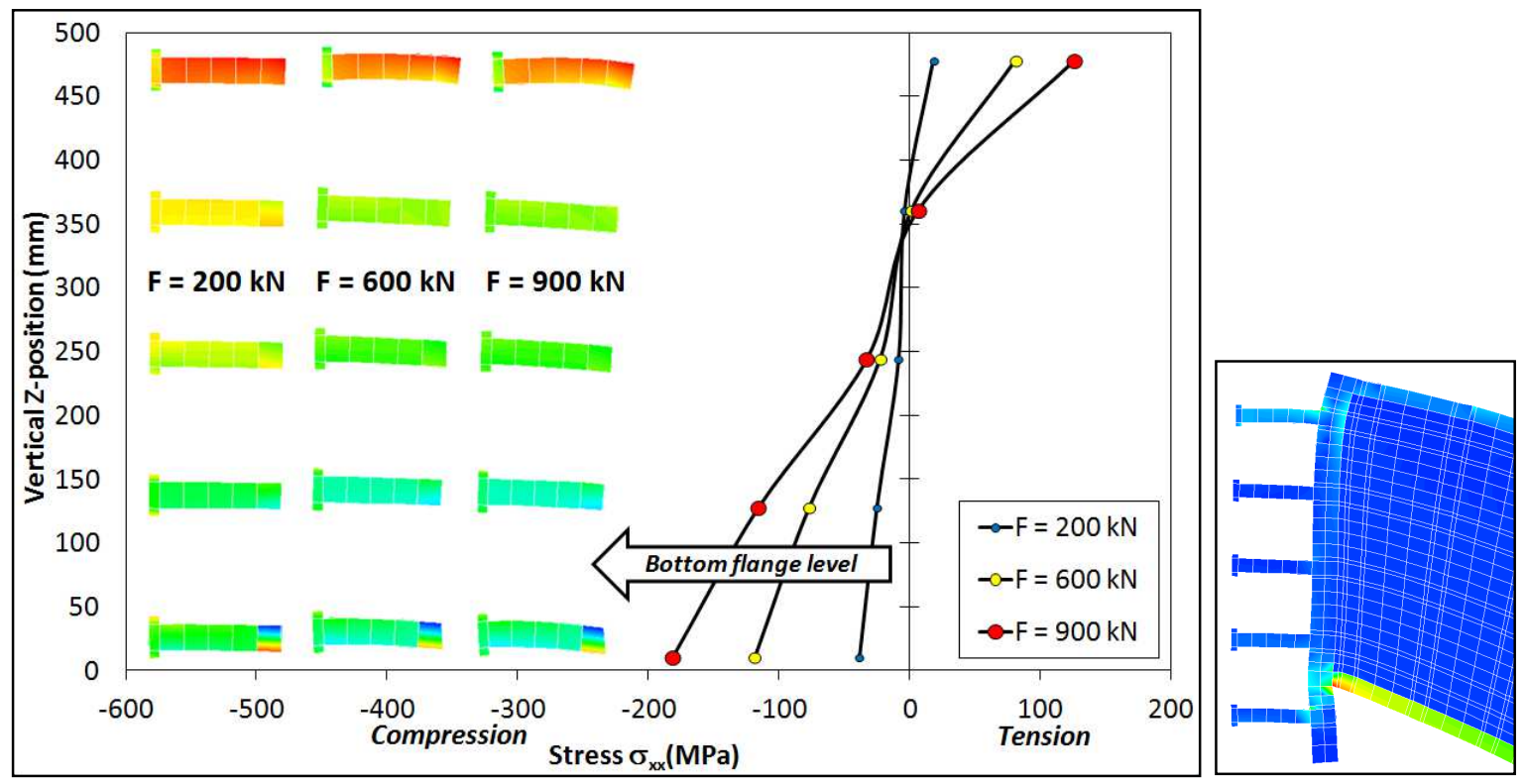

Figure 23 - Longitudinal stresses $\sigma_{\mathrm{xx}}$ at each horizontal stud-row.

\section{3 - Shear stresses in horizontal stud-rows}

Figure 24 shows shear stresses $\sigma_{\mathrm{xz}}$ plotted at each horizontal stud-row also for the experimental specimen (Case 2 in Section 6.1). One observes that the shear force $F$ is mostly supported by the bottom stud-rows. Referring to [15], the behaviour of this located zone subjected to a shear force is similar to the case of a standard push-out test. One distinguishes 3 parts of the shear force transmitted by the joint:

- First part supported by the horizontal stud-rows.

- Second part supported by the contact reaction of the transverse beam concrete located at the base of each stud-row.

- Third part supported by the friction between the butt-plate and the transverse beam.

The sum of these parts must be equal to the applied load $F$ to ensure the equilibrium. This analyze has been clearly developed in [15] in the case of push-out tests where equilibrium conditions were well verified. 


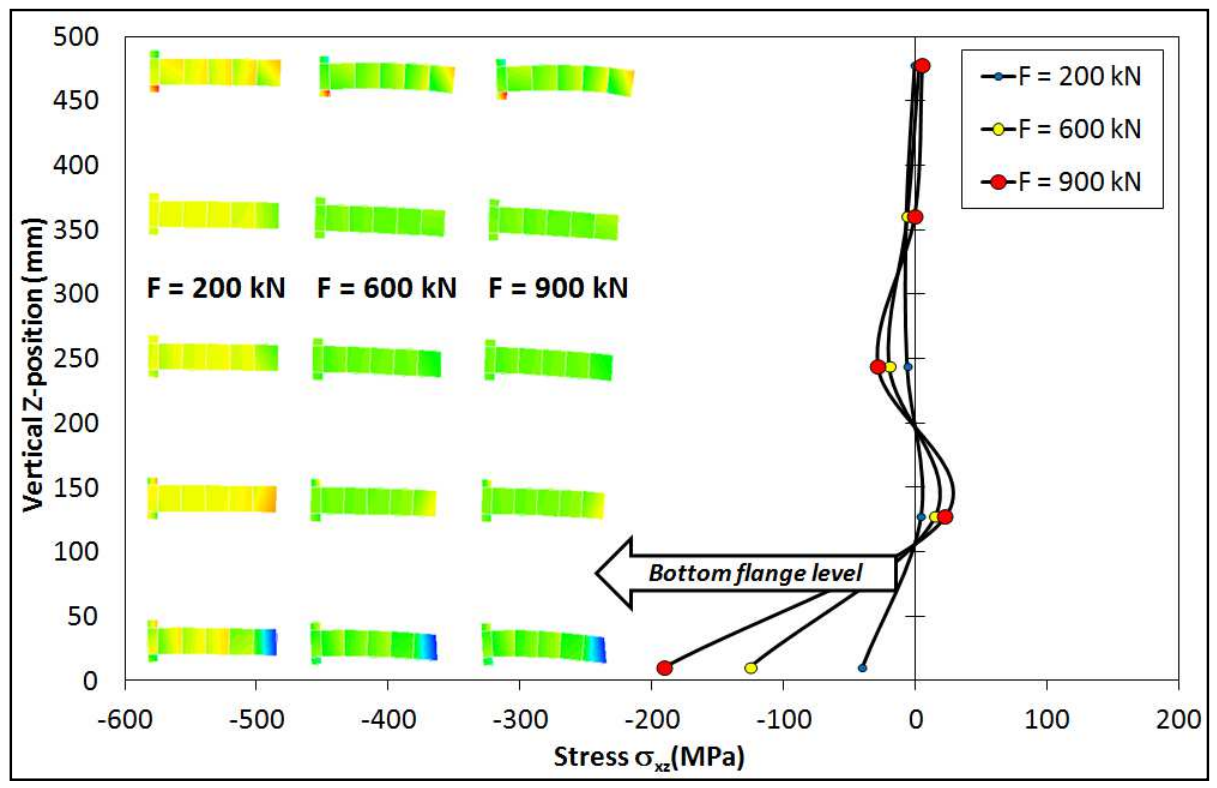

Figure $24-$ Shear stresses $\sigma_{\mathrm{xz}}$ at each horizontal stud-row.

In order to know the portion of the shear force supported by friction, one considers the difference: ( $\Sigma f=F-\Sigma W$ ) between the applied load $F$ and the total vertical force $\Sigma W$ transmitted by the studs. Considering the butt-plate as the isolated system, it is easy to verify that these values ( $\Sigma W$ in Table 5) are the sum of nodal vertical forces calculated from the shear stresses plotted in Figure 24 after multiplying them by corresponding depth $Y_{h}=176$ $m m$ (Table 3 - Material B) and by $d_{2}=22 \mathrm{~mm}$ (Table 1) corresponding to the diameter of stud. For each loading level $(F=200 \mathrm{kN}, F=600 \mathrm{kN}$ and $F=900 \mathrm{kN})$, Table 5 summarizes the percentage of the loads $\Sigma W / F$ and $\Sigma f / F$ transmitted by each part. It is clear that, for each value of $F$, the total force equilibrium must lead to:

$$
\frac{\sum W}{F}+\frac{\sum f}{F}=100 \%
$$

Table 5 - The shear force transfer.

\begin{tabular}{|c|c|c|}
\hline Load $F(k N)$ & $\frac{\sum W}{F}(\%)$ & $\frac{\sum f}{F}(\%)$ \\
\hline 200 & $185.8 / 200=93 \%$ & $(200-185.8) / 200=7 \%$ \\
\hline 600 & $509.2 / 600=85 \%$ & $(600-509.2) / 600=15 \%$ \\
\hline 900 & $741.9 / 900=82 \%$ & $(900-741.9) / 900=18 \%$ \\
\hline
\end{tabular}

In Table 5, one observes that the friction increases with the increasing of the applied load. Percentage of the forces transmitted by friction appears significant especially for $F \geq 600 \mathrm{kN}$. This friction is localized predominantly on the lower part of the butt-plate.

\section{CONCLUSIONS}

The main conclusions for the present work could be summarized as follows:

- It has been shown that the simplified 2D model, previously used to investigate pushout tests, is also an efficient tool for the analysis of such a type of joint as the one studied in this paper. 
- It has been shown that the developed 2D model allowed to perform parametric studies. Other parametric studies could be envisaged such as: the size of the studs, the percentage of reinforcement of the slab and the transverse beam... and could be the subject of a following paper.

- Main joint components affected by the increasing of butt-plate thickness have been clearly identified: tensile and compressive stresses in the transverse beam, shear forces and normal forces in the stud-anchor rows of the butt-plate and longitudinal stresses over the width of the steel girder web near the joint. A simplified design rule may be adopted in choosing a butt-plate thickness of about twice the flange thickness of the steel section of the composite beam seems to be a good compromise in order to limit concrete stresses due to the local compression in the transverse beam and not to increase too much the tensile stresses in the flanges of the steel section.

- The use of contact-friction elements is necessary to conclude on the part of shear force that is supported by friction in such a type of joint. It could be suitable to develop a 3D model to give more realistic values of this percentage (Table 5). Nevertheless, with this proposed simplified 2D-model a minimum of $10 \%$ of the applied load could be already considered. In view of these results, the position of EN1994-1-1 which consists to not add the frictional forces to the effect of the shear connectors appears safe in so far as the part of the frictional forces remains low and unsecured according to the values of the loading.

- A better understanding of the transfer-mechanism of internal forces in different components of the joint has been obtained from the developed numerical model; especially in the butt-plate, in the attached steel girder cross-section, in the studanchors, in the reinforcement of the slab and in the transverse concrete beam. The effect of the web fastening on the horizontal stud-anchor rows of the butt-plate has been also clearly observed.

\section{REFERENCES}

[1] ECCS STEEL RTD PROGRAM (CECA), Composite Bridge Design for Small and Medium Spans, RWTH-CTICM-PROFILARBED, Interim Report N², 2000.

[2] Lachal A., Aribert J.M., National Research Project MIKTI, Theme 1, Design of outstanding decks in the framework of small spans, Subject 1-B : Innovative techniques to connect continuous beams, specifications. Research report, February 2002.

[3] S. Guezouli, H. Somja, S.S. Kaing and A. Lachal, Numerical Modeling of composite beam-to-beam joints - Innovative solutions - Composite Construction VI (CCVI), Collorado, USA, July 2008. ASCE publication 2008.

[4] FINELG software, non-linear finite element analysis program developed at Department M\&S of Liège University, Belgium, 1999.

[5] CASTEM 2000, Un code de calcul aux éléments finis, CEA/DMT/LAMS, Sarclay, France, 2010.

[6] Ahmed B. Numerical modeling of semi-rigid composite joints. Ph.D. thesis. UK: University of Nottingham; 1996.

[7] Dunai L., Experimental and Numerical Studies on the Cyclic Behavior of Steel and Composite Joints, Steel Stuctures 4, 197-208, 2004.

[8] Fu F., Lam D., Ye JQ. Parametric study of semi-rigid composite connections with 3D finite element approach. Engineering Structures 2006.07.003. 
[9] Sieffert Y., Michel G., Ramondenc Ph., Jullien JF. Effects of the diaphragm at mid-span on static and dynamic behaviour of composite railway bridge: A case study. Engineering Structures 28 (2006) 1543-1554.

[10] Chung W., Sotelino E.D. Three-dimensional finite element modeling of composite girder bridges. Journal of Structural Engineering Structures 28 (2006) 63-71.

[11] Kalfas C., Pavlidis P., Load-slip curve of shear connectors evaluated by FEM analysis. International Conference, Composite Construction - Conventional and Innovative, Innsbruck, Austria, (1997) 151-156.

[12] El-lobody E., Lam D., Modelling of headed stud in steel-precast composite beams. Steel and Composite Structures, Vol. 2, No. 5 (2002) 355-378.

[13] El-lobody E., Young B., Performance of shear connection in composite beams with profiled steel sheeting. Journal of Constructional Steel Research 62 (2006) 682-694.

[14] Mirza O., Uy B., Effects of the combination of axial and shear loading on the behaviour of headed stud steel anchors. Engineering Structures 32 (2010) 93-105.

[15] Guezouli S. and Lachal A., Numerical analysis of frictional contact effects in push-out tests. Journal of Structural Engineering Structures 40 (2012) 39-50.

[16] Guezouli S., Lachal A. and Nguyen Q. H., Numerical investigation of internal force transfer mechanism in push-out tests. Journal of Structural Engineering Structures DOI: 10.1016/j.engstruct.2013.02.021.

[17] EN 1994-2 - Eurocode 4, Design of composite steel and concrete structures - Part 2 "General rules and rules for bridges". European committee standardisation, Brussels, February 2006.

[18] EN 1993-1-8:2003: Eurocode 3: Design of steel structures - Part 1-8 "Design of joints". European Committee for Standardization, Brussels, April 2005.

[19] EN 1992-1-1:2004: Eurocode 2: Design of concrete structures - Part 1-1 "General rules and rules for buildings". European committee standardisation, Brussels, 2004.

[20] EN 1994-1-1:2004: Eurocode 4: Design of composite and concrete structures - Part 1-1 "General rules and rules for buildings". European Committee for Standardization, Brussels, September 2004. 